\title{
The labour supply effect of Education Maintenance Allowance and its implications for parental altruism
}

\author{
Angus Holford
}

Received: 9 September 2014/ Accepted: 27 February 2015/Published online: 7 March 2015

(C) The Author(s) 2015. This article is published with open access at Springerlink.com

\begin{abstract}
Education Maintenance Allowance (EMA) was a UK government cash transfer paid directly to children aged 16-18, in the first 2 years of post-compulsory full-time education. This paper uses the labour supply effect of EMA to infer the magnitude of the transfer response made by the parent, and so test for the presence of an 'effectively altruistic' head-of-household, who redistributes resources among household members so as to maximise overall welfare. Using data from the Longitudinal Study of Young People in England, an EMA payment of $£ 30$ per week is found to reduce teenagers' labour supply by $3 \mathrm{~h}$ per week and probability of employment by $13 \%$ points from a base of $43 \%$. We conclude that parents withdraw cash and in-kind transfers from their children to a value of between 22 and $86 \%$ of what the child receives in EMA. This means we reject the hypothesis of an effectively altruistic head-of-household, and argue that making this cash transfer directly to the child produces higher child welfare than if the equivalent transfer were made to parents.
\end{abstract}

Keywords Education Maintenance Allowance - Altruism - Transfers · Rotten kid

JEL Classification $\mathrm{I} 38 \cdot \mathrm{J} 22 \cdot \mathrm{H} 53$

\section{Introduction}

Publicly provided transfers targeted at children are usually made in-kind or as a hypothecated cash transfer paid to parents. There are two mechanisms which may

\footnotetext{
A. Holford ( $\square)$

Institute for Social and Economic Research, University of Essex, Wivenhoe Park,

Colchester CO4 3SQ, UK

e-mail: ajholf@essex.ac.uk
} 
mitigate the benefit from these transfers to the intended recipient. Firstly, if the transfer is paid to the parent, there is an agency problem: The parent is not compelled to spend the benefit on the child. For example, Blow et al. (2012) find that unanticipated variation in the level of Child Benefit in the UK affects expenditure predominantly on adult-assignable goods, while Kooreman (2000) finds strong positive effects of the Dutch Child Benefit on child-assignable goods. (The 'labelling effect' of the programme's name clearly differs between these countries - see Beatty et al. 2014). It also matters which parent receives the welfare payment, with a switch from father to mother ('wallet to purse') being shown to raise expenditure on child care and children's clothing, and reduce expenditure on alcohol and tobacco, for example (Lundberg et al. 1997; Phipps and Burton 1998). Secondly, regardless of who receives the transfer, parental altruism may substantially offset the gain to the targeted household member, as an altruistic head-ofhousehold may redistribute resources among household members so as to maximise household welfare (Becker 1974, 1981). In this case, an in-kind transfer may still benefit the child if the household is induced to consume more of the good than it would voluntarily (Currie and Gahvari 2008), or if the parent does not perceive the publicly provided good to be a close substitute for a privately provided good. For example, Bingley and Walker (2013), show that day care milk or milk tokens in the UK crowd out private expenditure on milk (an essentially homogeneous product) to $80 \%$ of these transfers' value, but Free School Meals (for which there is no close market substitute) only crowd out expenditure on food to $15 \%$ of their value. Nevertheless, von Hinke Kessler Scholder (2013) finds no effect of the withdrawal of Free School Meals from some groups on their bodyweight, suggesting that targeted children receive no better an overall diet than in the absence of the programme.

The extent to which the incidence of the net benefit of a transfer programme is retained by the targeted recipient is referred to as the 'Intrahousehold Flypaper Effect' (Jacoby 2002). In this paper we evaluate the magnitude of this effect for the UK's Education Maintenance Allowance (EMA) programme. EMA was a meanstested cash transfer of up to $£ 30$ per week paid by the UK government to students undertaking the first 2 years of full time post-compulsory education (aged 16 or 17 on 31st August at the start of the school year). Eligibility was determined by household income, according to the thresholds shown in Table 1. ${ }^{1}$ At its peak in the 2009-2010 school year the scheme cost $£ 580 \mathrm{~m}$ and served 643,000 recipients (see Bolton 2011, p. 2).

EMA differs from most high profile conditional cash transfers (CCTs), such as Bolsa Família in Brazil, Opportunidades in Mexico, and Opportunity NYC in the United States, in two ways. Firstly, it is a late intervention, targeting the continued human capital development of 'children' (in fact young adults) beyond the compulsory schooling age, rather than school attendance or health programme

\footnotetext{
1 Income earned by the child through part-time work or their own welfare receipt was disregarded. These thresholds and entitlements were unchanged in nominal terms over the scheme's life in England, 2004-2011.
} 
Table 1 Eligibility thresholds for EMA

\begin{tabular}{ll}
\hline Household income, per year & EMA entitlement, per week \\
\hline$<£ 20,818$ & $£ 30$ \\
$£ 20,818-£ 25,521$ & $£ 20$ \\
$£ 25,522-£ 30,810$ & $£ 10$ \\
$>£ 30,810$ & Zero \\
\hline
\end{tabular}

participation among primary-age children. Secondly, it is paid straight to the child, rather than to the mother.

Paying CCTs to the mother requires her agency, to pass the (benefits of the) transfer to the intended recipient, on behalf of the state. Because EMA was paid directly to the child, there is no agency problem. This and several other contextual features make EMA ideal to investigate the extent of crowd-out of private transfers by this public transfer, and to attribute this effect to the mechanism of parental altruism. EMA was paid in cash, which is a perfect substitute for cash transfers from parents, and for the parents' own income. Moreover, barriers to participation were low (students needed a bank account in their name and a parental declaration of income once each academic year) and stigma unlikely to be a problem (the eligibility criteria were wide and take-up high-in our data $86 \%$ of those apparently eligible for the highest payment, and $45 \%$ of all students, receive EMA), so conditional on participation in full-time education the direct non-pecuniary costs associated with receipt of the benefit should be negligible. The intervention was also of a substantial economic magnitude, both for the child and the household. For example, the highest weekly EMA payment of $£ 30$ per week during term times was larger than the mean weekly earnings of teenagers in employment during their final year of compulsory schooling in the LSYPE (£27.76), and corresponds to a tax free increase in the household's full income of up to $£ 1170$ per year, or a minimum of $5.6 \%$ of parent's income for those in the lowest income eligibility bracket. Altogether, this means that the parent's transfer response to EMA should provide a clean test of whether the parent's behaviour is consistent with that of an effectively altruistic head-of-household.

The extent to which the public transfers are crowded out by family transfers is usually evaluated using data on household expenditure patterns for 'child-assignable goods' (Kooreman 2000; Hoddinott and Skoufias 2004; Attanasio and Mesnard 2006; Blow et al. 2012). A challenge to the identification of this degree of crowd-out is lack of (or measurement error in) data on (the value of) shared services or in-kind transfers within private households. For this reason, one approach is to focus on units of the extended family that are not co-resident, and so in which the shared services can be assumed to be zero. For example, Jensen (2003) showed that each unit increase in public pension income in South Africa reduced receipt of private transfers from the pensioner's children living outside the home by $0.20-0.30$ units. However, when considering public transfers paid to young adults, co-residence is likely to represent a significant proportion of the support received from their parents. Rosenzweig and Wolpin (1994), for example, use changes in welfare rules over time and between states to show that a $\$ 1000$ increase in Aid for Families with 
Dependent Children (AFDC) by young women with children reduces their probability of receiving financial aid from their parents by $3.4 \%$, and of coresiding by $4.7 \%$. While this provides evidence that the net benefit of the AFDC programme is mainly captured by its recipients, the authors' data do not enable them to identify the effective rate at which parents 'tax' their children's benefit receipt.

All students in our sample are co-resident with a parent, ${ }^{2}$ but we do not have data on cash transfers made by parents to children receiving EMA, and we expect additional unobserved heterogeneity in in-kind transfers or the items that children are expected to purchase themselves. We therefore propose an alternative strategy to identify the net change in the child's opportunity set, which does not depend on any survey instruments designed to capture intrahousehold transfers. Our identification strategy instead stems from the insight, formalised in the theoretical model set out in Sect. 2, that if parents respond to the child's receipt of EMA by withdrawing cash and in-kind transfers of an equal value (consistent with the parent 'fully insuring' the child's consumption), then the child's opportunity set is unchanged, and he should not alter his labour supply. Correspondingly, the larger the child's reduction in labour supply, the smaller the redistributive response made by parents, or equivalently, the greater the proportion of the EMA the child has been permitted to keep.

We use data from the Longitudinal Study of Young People in England (LSYPE), deposited by the Department for Education and National Centre for Social Research (2012). We observe the labour supply and EMA receipt of a cohort of individuals in their final year of compulsory schooling (during which no-one received EMA) and first 2 years of post-compulsory schooling (during which teenagers whose parents met the income criteria were eligible to receive EMA). Our data are outlined in detail in Sect. 3, below. To pre-empt our results, estimates from linear, Tobit and logistic regression methods in both cross-sectional and panel data frameworks firmly reject a model of effectively altruistic parents. An EMA payment of $£ 30$ per week reduces teenage labour supply by between 2.4 and $3.2 \mathrm{~h}$ per week at the intensive margin. These results are robust to estimation on the sub-sample of noncredit-constrained households, for whom we argue participation in post-compulsory education is unlikely to be affected by eligibility for EMA. Using estimates of teenagers' labour supply response to unearned income obtained from elsewhere in the literature (Dustmann et al. 2009; Wulff Pabilonia 2001), we calculate this to be consistent with parents withdrawing cash and in-kind transfers from the child to between 22 and $86 \%$ of the value of EMA.

While the (non-) altruistic behaviour of parents has implications for the targeting of transfers-our results indicate that the child's welfare benefit from EMA is higher than had an equivalent transfer been made to parents- the labour supply effect of EMA has implications for the efficacy of conditional cash transfers in raising educational performance. In-school employment is widespread. In our data, $43 \%$ of 17 year-olds in the first year of post-compulsory education are in employment. In-school employment may improve teenagers' stock of cognitive and non-cognitive human capital (for example, financial literacy, communication skills

\footnotetext{
$\overline{2}$ We drop teenagers in social care from our sample.
} 
and lower discount rates-Oettinger 1999; Light 2001) or preference for education as a route to higher-skilled work in future (Dustmann and van Soest 2007). However, by crowding out time and effort devoted to study (e.g. Kalenkoski and Wulff Pabilonia 2013) it may reduce the child's educational performance, particularly above a moderate number of hours per week or in close proximity to high-stakes examinations (Lillydahl 1990; Ruhm 1997; Payne 2004). Hence, to the extent that EMA reduces labour supply at least at the higher end of the working hours distribution, this should feed through to an improvement in their academic and future labour market outcomes. ${ }^{3}$

While there are indications from hypothetical questions that EMA reduced recipients' labour supply (RCU Market Research 2007), to our knowledge we are the first to quantify this labour supply effect using observational data. Although EMA closed to new applicants in England in January 2011, it was replaced by the '16-19 bursary' programme, with a smaller budget of $£ 180 \mathrm{~m}$, and automatic entitlement reduced in scope to approximately 12,000 of the "most vulnerable" students. EMA has been retained in the rest of the UK. It will be important for policymakers to account for the labour supply effect of this scheme in considering any future reforms.

The remainder of this study is structured as follows: Part 2 sets out a model showing how the labour supply response to EMA provides a test for the presence of an effectively altruistic head-of-household. Part 3 discusses the data and estimation strategy, Part 4 presents the results and Part 5 sets out the conclusions and recommendations.

\section{Theoretical and empirical model}

In this section we develop a theoretical model for the joint determination of parental transfers and the child's labour supply. We follow closely the structure of Dustmann et al. (2009) and Kalenkoski and Wulff Pabilonia (2010) but extend their analysis to account for (1) the introduction of EMA - an exogenous cash transfer paid to the child-and (2) endogenous selection into post-compulsory education as a function of potential receipt of EMA, parental transfers and labour supply.

We assume that if the child is not in full-time education he will earn the utility $\bar{U}_{0}$, which we treat as exogenously determined. If $\bar{U}_{0}$ exceeds the maximum utility attainable from being in full-time education, as determined by the model we now outline, the child will leave full-time education. We return to the issue of endogenous selection into post-compulsory education in Sect. 2.2.

Our structural parameter of interest is the amount $\lambda$, by which parental transfers are reduced for every pound the child receives in EMA. We face the challenge that there exist no data on cash transfers received by LSYPE sample members in postcompulsory education. More broadly however, even where information on cash transfers is elicited, researchers typically still lack data on in-kind transfers and the items which children are expected to pay for themselves, which are required for

\footnotetext{
$\overline{3}$ We do not evaluate this effect directly, and discuss the challenges in doing so in our conclusions.
} 
complete identification of models of parental altruism. ${ }^{4}$ Our model shows how the child's labour supply response to EMA can be used for inference about parents' withdrawal of both cash and in-kind transfers.

We assume two agents; a selfish child and altruistic parent. Each holds full information about the preferences of the other. Both wish to maximise the present value of their expected lifetime utility. The parent's altruism may be impure, in that she values the child's academic performance more highly than does the child. Each agent may discount future utility at different rates, or hold distinct beliefs about how current behaviour will impact upon future opportunities.

The parent announces a contingent rule specifying the baseline transfer she will make if the child is in full-time education and working zero hours $T$, and the amount by which the transfer will be reduced for every pound the child earns in the labour market $t$. It is costless to set and revise the transfer level. (Any announcement or child's expectation about the support to be provided if the child is not in full-time education is built into the reservation utility $\bar{U}_{0}$ ).

The child is assumed to have no bargaining power. His outside option or threat point, known to the parent, is the utility gained from leaving full-time education $\bar{U}_{0}$. The parent's preference for the child's academic performance gives the child scope to extract bargaining power through the threat to withdraw from full-time education. However, here we follow Burton et al. (2002) and Schmidt (1993) in assuming that the parent has developed a reputation, and that the child's discount rate is sufficiently high that he takes the parent's strategy as given. This means the child cannot credibly commit to this self-damaging action.

Taking this parental strategy as given, the child then chooses his labour supply $1 \in[0,1]$ at a constant wage $w$ (and effective wage $(1-t) w$ ), to maximise his utility function $U(C, L)$ defined over consumption $(C)$ and leisure $(L)$, which comprises all non-labour market activities. Normalising the total time available to unity $\operatorname{imposes} L=1-1$. The function $U(C, L)$ is assumed to be strictly increasing, twice differentiable and strictly quasiconcave in its arguments. The child's concerns regarding future consumption or academic performance are nested within his utility from leisure.

Without EMA, the child's only source of unearned income, $\omega$, is the transfer from parents. Rewriting $U$ in terms of labour supply, the child's problem can be defined as:

$$
\max _{C, 1} U(C, 1-l) \quad \text { subject to } \quad C \leq T+(1-t) w 1
$$

Assuming that leisure is a normal good over the relevant domain ensures that the child's optimal labour supply $1 *$ is non-increasing in unearned income, $\omega$, and strictly decreasing for for $1 *>0$ :

\footnotetext{
4 The age 16 sweep of the UK's National Child Development Study of a cohort born in 1958 and studied by Dustmann et al. 2009, is an exception.
} 


$$
\begin{aligned}
& \frac{\partial \mathrm{l} *}{\partial \omega} \leq 0 \quad \text { if } 1 * \geq 0 \\
& \frac{\partial \mathrm{l} *}{\partial \omega}<0 \quad \text { if } 1 *>0
\end{aligned}
$$

We also assume that optimal labour supply is non-decreasing in the effective wage, $(1-t) w$, and strictly increasing for $1 *>0$ :

$$
\begin{aligned}
& \frac{\partial 1 *}{\partial((1-t) w)} \geq 0 \quad \text { if } 1 * \geq 0 \\
& \frac{\partial 1 *}{\partial((1-t) w)}>0 \quad \text { if } 1 *>0
\end{aligned}
$$

The child will undertake paid employment if and only if the effective wage exceeds the marginal rate of substitution of leisure for consumption at the initial endowment point. Formally this may be expressed as:

$$
\begin{gathered}
1^{*}>0 \quad \text { iff }(1-t) w>\frac{\partial U(T, 1) / \partial L}{\partial U(T, 1) / \partial C} \\
1^{*}=0 \quad \text { iff }(1-t) w \leq \frac{\partial U(T, 1) / \partial L}{\partial U(T, 1) / \partial C}
\end{gathered}
$$

Finally, we define for each child a reservation utility $\bar{U}_{0}$, equal to that which could be obtained by leaving full-time education. If this is not attainable at the optimum position, the child will not participate in post-compulsory full-time education.

This model formalizes the stylized facts from the literature (Dustmann et al. 2009; Kalenkoski and Wulff Pabilonia 2010; Wolff 2006; Gong 2009) that, conditioning on the child being in full-time education, (1) parents provide smaller transfers, or are less likely to provide positive transfers, the more the child works, other things equal, and (2) children undertake less employment, the greater the transfer received from parents, other things equal. Equations (1-4) also accommodate a discrete choice framework wherein the probability of working positive hours is non-increasing in unearned income and non-decreasing in the effective wage. A discrete framework may be more appropriate if employers are unwilling to hire individuals for less than a minimum number of hours each week.

Retaining the notation developed above, the model is summarised in Figs. 1 and 2. Reservation utility (that which the child would gain by leaving compulsory education) is represented by indifference curve $\mathrm{IC}_{0}$. Higher indifference curves represent higher utility. The budget constraint (BC) represents the upper bound of the child's opportunity set for $1>0$. Interior optima are defined by the tangency of budget constraint and indifference curve. Figure 1 shows the case with a fixed lumpsum transfer $\left(\mathrm{T}_{1}\right)$, and a varying 'tax rate' on the child's earnings $(t)$. Here, the lump-sum transfer $T_{1}$ is just sufficient to ensure that the child does not need to take employment in order to meet his education participation constraint. The parent can then induce zero hours of work by 'taxing' the child's income at a rate of $100 \%$ 
Fig. 1 Labour supply with $\omega=\mathrm{T}_{0}$ and $\mathrm{t}$ varying (fixed lump-sum transfer, varying 'tax rate')

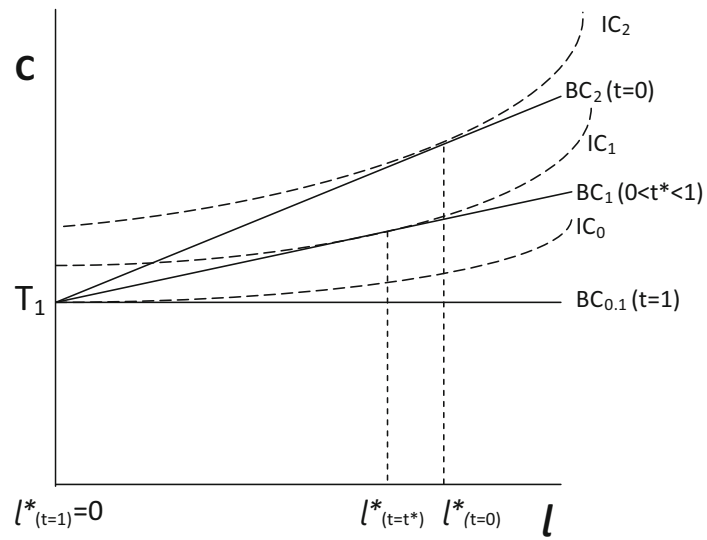

(setting $t=1$ ), while still ensuring the child stays in education. Reducing $t$ raises the effective wage, increasing the slope of the budget constraint and improving the child's welfare as higher indifference curves become attainable. In line with our assumption in Eq. (3), reducing the tax rate and raising the effective net wage is here shown to induce longer hours of work.

Figure 2 shows the case with a fixed tax rate $\left(t=t^{*}\right)$, but varying the size of the initial lump-sum transfer. A child offered $\mathrm{T}_{1}$ will, at zero hours of work, be indifferent between staying in and leaving full-time education, but by undertaking his optimum labour supply $1^{*}\left(\omega=\mathrm{T}_{1}\right)$ will have strictly higher utility than the reservation level. A child in this situation will therefore continue in full time education. His welfare can be further improved by raising the lump sum transfer to $\mathrm{T}_{2}$. In line with our assumption in Eq. (2), conditioning on meeting the participation constraint, increasing the child's unearned income is here shown to induce shorter hours of work. In Fig. 2 however, a child offered $\mathrm{T}_{0}$, for example, cannot attain his reservation utility at any level of employment. Without additional financial support from outside the household, he will leave full time education.

Fig. 2 Labour supply with $\mathrm{t}=\mathrm{t}^{*}$ and $\omega$ varying (varying lump-sum transfer, fixed 'tax rate')

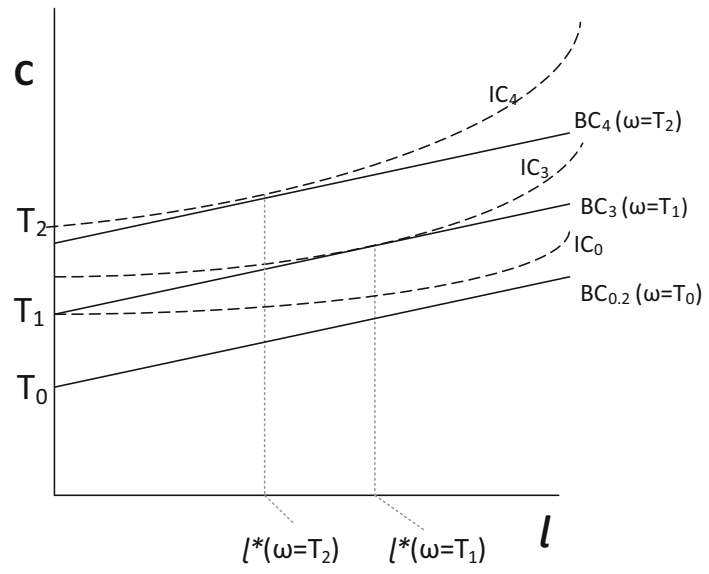




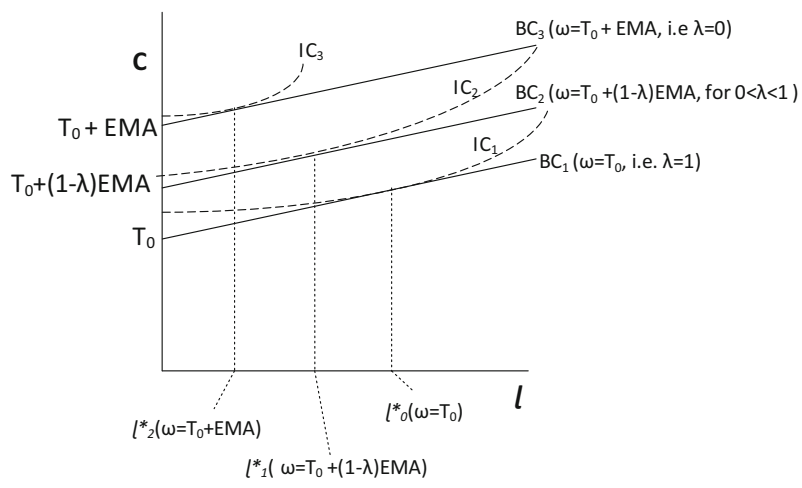

Fig. 3 Introducing EMA to the labour supply model

\subsection{Introducing EMA}

Let us then introduce an additional source of unearned income paid straight to the child; EMA. We first consider the situation of an individual whose educationparticipation constraint is satisfied without EMA. For this group, EMA can be treated as exogenous, conditional on the parent's income. (The maximum annual difference in EMA payments from moving into a lower income bracket— $£ 390$ - is too small for parents profitably to 'fine-tune' their true income).$^{5}$

In Fig. 3, EMA initially induces a vertical upward shift in the child's budget constraint. However, in response, the parent may choose to reduce the transfer $T$ by some proportion $\lambda \in[0,1]$ of the value of EMA received by the child. (A lower $\lambda$ permits the child to 'keep' an increasing proportion of his EMA). The expression for the child's unearned income is now:

$$
\omega=T+(1-\lambda) \cdot \mathrm{EMA}
$$

The parent's response to earned income, defined by $t$, is assumed not to change. The child's problem can now be written:

$$
\max _{C, l} U(C, 1-l) \text { subject to } C \leq T+(1-\lambda) \mathrm{EMA}+(1-t) w l
$$

If $\lambda=1$, the child's EMA is entirely offset by an equivalent reduction in the transfer from the parent. This leaves the child's budget constraint unchanged compared with the initial situation. With the same opportunity set, the child's working hours should also remain unchanged. Hence, if we observe a negative labour supply response to EMA, this implies $\lambda<1$, and we can reject the null hypothesis of 'full insurance', or parents isolating their children from any income variation. ${ }^{6}$ However, as EMA is an exogenous payment to the child, it does not

\footnotetext{
$5 £ 10$ per week, 39 weeks per year.

${ }^{6}$ Failure to reject a labour supply response of zero is not sufficient to conclude that parents are fully insuring their children. This could result from an income-elasticity of labour supply of zero. However, a negative labour supply response is sufficient to reject both an income elasticity of zero and full insurance.
} 


\section{Key:}

Reservation Utility, $I C_{0}$ :

Budget Constraint without $\mathrm{EMA}, \mathrm{BC}_{\mathrm{N}}$ :

Effective Budget Constraint with $E M A, B C_{\mathrm{E}}$ :

$$
\begin{aligned}
& C=T_{0}+(1-t) w l \\
& C=T_{0}+(1-t) w l+(1-\lambda) E M A
\end{aligned}
$$
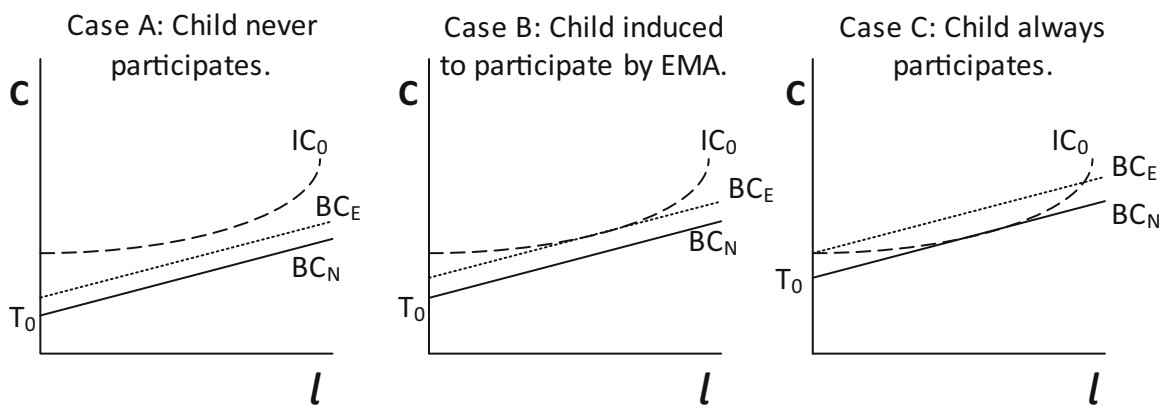

Fig. 4 How EMA may affect the decision to participate in post-compulsory education

constitute a zero-sum redistribution of household resources. This means that to reject a null hypothesis of an effectively altruistic parent (who redistributes resources so as to maximise household welfare) we must reject $\lambda \geq(1-\theta)$, where $\theta$ is the parent's marginal propensity to transfer to the child out of her own income. We do not have the data to test this directly, but present back-of-the-envelope calculations appealing to results elsewhere in the literature.

\subsection{Endogenous selection into full-time education}

The policy objective of EMA was to increase participation in post-compulsory education. Dearden et al. (2009) provide an evaluation based on a pilot scheme in matched areas of England, and concluded that EMA raised participation by eligible young people in the first year of post-compulsory schooling by 4.5 percentage points, from a base of $65 \%$. The effect was larger among children living in rented accommodation or social care. The authors suggest this provides evidence that the principal mechanism by which EMA increases participation is by easing credit or liquidity constraints rather than simply reducing the opportunity cost of education.

In our model, the condition for EMA to induce a child to stay in full-time education is illustrated in case B of Fig. 4. Net of the parent's response, adding EMA to the child's effective budget constraint must make the reservation utility newly attainable. If the initial parental transfer were any smaller than in case $\mathrm{B}$, the child would still be worse-off in full-time education and receiving EMA than if he dropped out (case A). On the other hand, if the initial parental transfer were sufficiently larger the child would continue in full-time education even without EMA (case C). EMA is therefore a binding consideration in the education participation decision of only a narrow group of people.

Nevertheless, it is clear that the treated group (receiving EMA) is fundamentally different to the non-treated group in that it contains some individuals ('inducees') 
who are only present in full time education because they receive EMA. The nontreated group (non-recipients in full-time education) only contains individuals who would have continued in full time education without EMA.

In the LSYPE, household income for the first year of post-compulsory schooling is recorded only in bands. The thresholds of these do not accord with those for EMA eligibility, and the period which income is recorded does not correspond to that over which eligibility is determined. Moreover, no information on parental income is collected at all during the second year of post-compulsory schooling. (Considerable information is instead collected on own income and benefit receipt among those cohort members who had left full-time education). This makes it impractical to assign a counterfactual EMA status for those who did not continue in education and thus model the role of EMA in the selection process empirically. Instead, we present a series of empirical specifications and show that our results are robust to a series of assumptions under which the bias caused by inducees (or indeed, other unobserved differences between EMA recipients and non-recipients) is eliminated.

Dearden et al. (2009, p. 837) argue that most inducees were drawn from "financially unproductive activities" rather than paid work. This suggests that the type of individual for whom EMA makes a difference to continued education is poorly motivated with respect to labour market activities, or more likely to live in deprived areas where there are fewer opportunities to work. We are able to proxy for local labour market opportunities using regional dummies and the Index of Multiple Deprivation for the child's area of residence. Assuming there is no residual difference in unobserved motivation between recipients and non-recipients, our separate crosssectional estimates for students in the first (wave 4) and second (wave 5) years of postcompulsory schooling will be unbiased. However, if, conditional on our set of individual and household characteristics, the child's motivation is positively correlated with hours of work and negatively correlated with EMA, the estimated labour supply effect of EMA will be downward biased. In addition, therefore, we control for time invariant differences in unobserved individual motivation or labour market opportunities using fixed-effect regression and conditional fixed-effect logit models. We also re-estimate our models using non-credit-constrained households, who we argue will not have been influenced by EMA when making their education participation decision, and show that the labour supply effect of EMA for this group does not significantly differ from that for the general population. We undertake additional robustness and sensitivity analyses by estimating on the sub-sample of male and female cohort members, and those interviewed during school term time.

\section{Data}

We use data from the Longitudinal Study of Young People in England (LSYPE), which tracked a cohort of individuals born between 1st September 1989 and 31st August 1990, and so in the same academic year at school. We use data from the third wave, conducted mainly in March-June of 2006, when respondents were 15 or 16 years old and in their final year of compulsory education, and the fourth and fifth waves, conducted mainly in June-July of 2007 and 2008 when respondents were 
16-17 and 17-18 years old and those continuing in post-compulsory education were in their first and second years respectively. In wave 4, of the 11,801 respondents, 8971 were in full time education. 4359 of these received EMA and 3795 reported positive hours of paid employment. Corresponding figures for wave 5 are 10,430 (reflecting sample attrition), 6953 (additionally reflecting dropout from full-time education), 3384 (take-up of EMA remained the same among those still in education) and 3632 (so a larger proportion of those in education had a part-time job at wave 5 than wave 4). There are no data documenting cash or in-kind transfers from parents, and what the child is required to pay for himself. We do observe the level of EMA received and their usual weekly hours of paid employment.

The profile of EMA take-up against household income in both waves 4 and 5 of the LSYPE, together with raw sample numbers, is shown in Table 2. Our data show substantial numbers of both students who would be eligible for EMA according to their current or previous year's household income but do not receive EMA, and apparently ineligible students who do receive EMA. Those in the second group may have experienced a rise in family income after having applied for EMA, but retained their entitlement until the end of the academic year (only then must they reapply). They may instead have obtained EMA through false reporting of household income, or be reporting income in the survey with error.

Non-take-up will partly depend on observed characteristics. For example, the informational demands when applying for EMA are greatest for those with selfemployed parents, and the opportunity cost of parents' time (to help with the

Table 2 Take-up of EMA in estimation sample, by household income band and entitlement bracket

\begin{tabular}{|c|c|c|c|c|c|c|c|}
\hline \multirow{3}{*}{$\begin{array}{l}\text { Annual household } \\
\text { income band (measured } \\
\text { in wave } 4 \text { ) }\end{array}$} & \multicolumn{7}{|c|}{ Conditional on participation in full-time education } \\
\hline & \multicolumn{3}{|l|}{ Wave 4} & \multicolumn{3}{|l|}{ Wave 5} & \multirow{2}{*}{$\begin{array}{l}\text { Weekly } \\
\text { EMA } \\
\text { entitlement }\end{array}$} \\
\hline & $\begin{array}{l}\text { Sub- } \\
\text { sample } \\
\text { size }\end{array}$ & $\begin{array}{l}\text { EMA } \\
\text { recipients }\end{array}$ & $\begin{array}{l}\text { EMA } \\
\text { take-up } \\
(\%)\end{array}$ & $\begin{array}{l}\text { Sub- } \\
\text { sample } \\
\text { size }\end{array}$ & $\begin{array}{l}\text { EMA } \\
\text { recipients }\end{array}$ & $\begin{array}{l}\text { EMA } \\
\text { take-up } \\
(\%)\end{array}$ & \\
\hline$<£ 2600$ & 74 & 56 & 75.68 & 48 & 39 & 81.25 & $£ 30$ \\
\hline$£ 2,600-£ 5,199$ & 220 & 180 & 81.82 & 150 & 122 & 81.33 & \\
\hline$£ 5200-£ 10,399$ & 617 & 573 & 87.03 & 422 & 355 & 84.12 & \\
\hline$£ 10,400-£ 15,599$ & 834 & 711 & 85.25 & 543 & 457 & 84.16 & \\
\hline$£ 15,600-£ 20,799$ & 698 & 580 & 83.09 & 474 & 390 & 82.28 & \\
\hline$£ 20,800-£ 25,999$ & 675 & 491 & 72.74 & 438 & 315 & 71.92 & $\begin{array}{l}£ 10, £ 20 \text { or } \\
£ 30\end{array}$ \\
\hline$£ 26,000-£ 31,199$ & 664 & 371 & 54.37 & 448 & 236 & 52.68 & Zero or $£ 10$ \\
\hline$£ 31,200-£ 36,399$ & 525 & 134 & 25.52 & 365 & 69 & 18.90 & Zero \\
\hline$£ 36,400-£ 41,599$ & 461 & 67 & 14.53 & 325 & 37 & 11.38 & \\
\hline$£ 41,600-£ 46,799$ & 417 & 36 & 8.63 & 284 & 22 & 7.75 & \\
\hline$£ 46,800-£ 51,999$ & 410 & 23 & 5.61 & 281 & 15 & 5.34 & \\
\hline$\geq £ 52,000$ & 1405 & 36 & 2.56 & 1011 & 19 & 1.88 & \\
\hline All & 7000 & 3212 & 45.89 & 4789 & 2076 & 43.35 & \\
\hline
\end{tabular}

Contains all observations for which neither household income nor EMA receipt entries are missing 
application) is likely to be related to their income and occupation. An omitted variables bias will occur if receipt of EMA is partially correlated with omitted variables that also help determine working hours. For example, more highly motivated teenagers are likely to pursue the application process most ardently, while also being likely to work longer hours, other things equal. This will positively bias the labour supply effect of EMA.

Hourly wages are not directly elicited. Instead of introducing measurement error by dividing weekly earnings by weekly hours, and necessitating a selection model (since the counterfactual wage of those not in employment is not observed), we omit wages from our model and assume they are partially uncorrelated with receipt of EMA. This assumption seems plausible. As argued by Wolff (2006), the teenagers considered here are likely to work predominantly at fixed hourly rates of pay close to the legal minimum wage. Motivation or any other unobserved personality traits, which may also affect receipt of EMA, are unlikely to be rewarded with higher wages.

We do control for a full range of covariates that might be expected to influence the child's and/or parent's attitudes to the child's employment and study, the parents' attitudes to transfers, and local labour market conditions. These include housing tenure, a measure of local deprivation, the employment status and qualifications of the parents, and household income. We include household income in our models with terms for the midpoint of the reported income band, its square, and a dummy each for missing and topcoded observations. ${ }^{7}$ Household income is not recorded in wave 5, so we substitute the wave 4 value. We discuss the bias this induces in each specification in the results section. As the survey is linked to the National Pupil Database, we can also control for prior educational performance up to age 16.

Sample descriptive statistics for selected explanatory variables are set out in Table 3. Here, we show that participation in full-time education tends to be lower among those living in deprived areas or lower income households, or those with parents from lower educational backgrounds. Participation is also substantially lower among males than females, and among those whose parents are 'creditconstrained'; defined in accordance with Dearden et al. (2009), as those living in rented accommodation or social care; than those who are not.

Among those participating in full-time education, those in employment are positively selected by socio-economic background. Children from progressively higher income households have higher unconditional mean hours of work and a greater probability of working positive hours, except at the very highest income band in wave 4 (a flattening off at around $58 \%$ occurs from a lower band in wave 5). A similar pattern is observed in relation to local deprivation (in wave 4 children from more affluent areas work more, until reaching the least deprived quintile, while in wave 5 the pattern is monotonic) and parental qualifications (the tendency to work is lowest for the children of parents with no qualifications, rising for those of parents with GCSEs (age 16) and A-Level (age 18 or university entrance) qualifications in turn, but falling again for those of parents with degrees).

\footnotetext{
7 Results, not shown for reasons of space, do not change if dummies for each income band are used instead, though standard errors are marginally greater with this less parsimonious approach, in which the degree of collinearity with the lower income bands and EMA receipt is higher.
} 


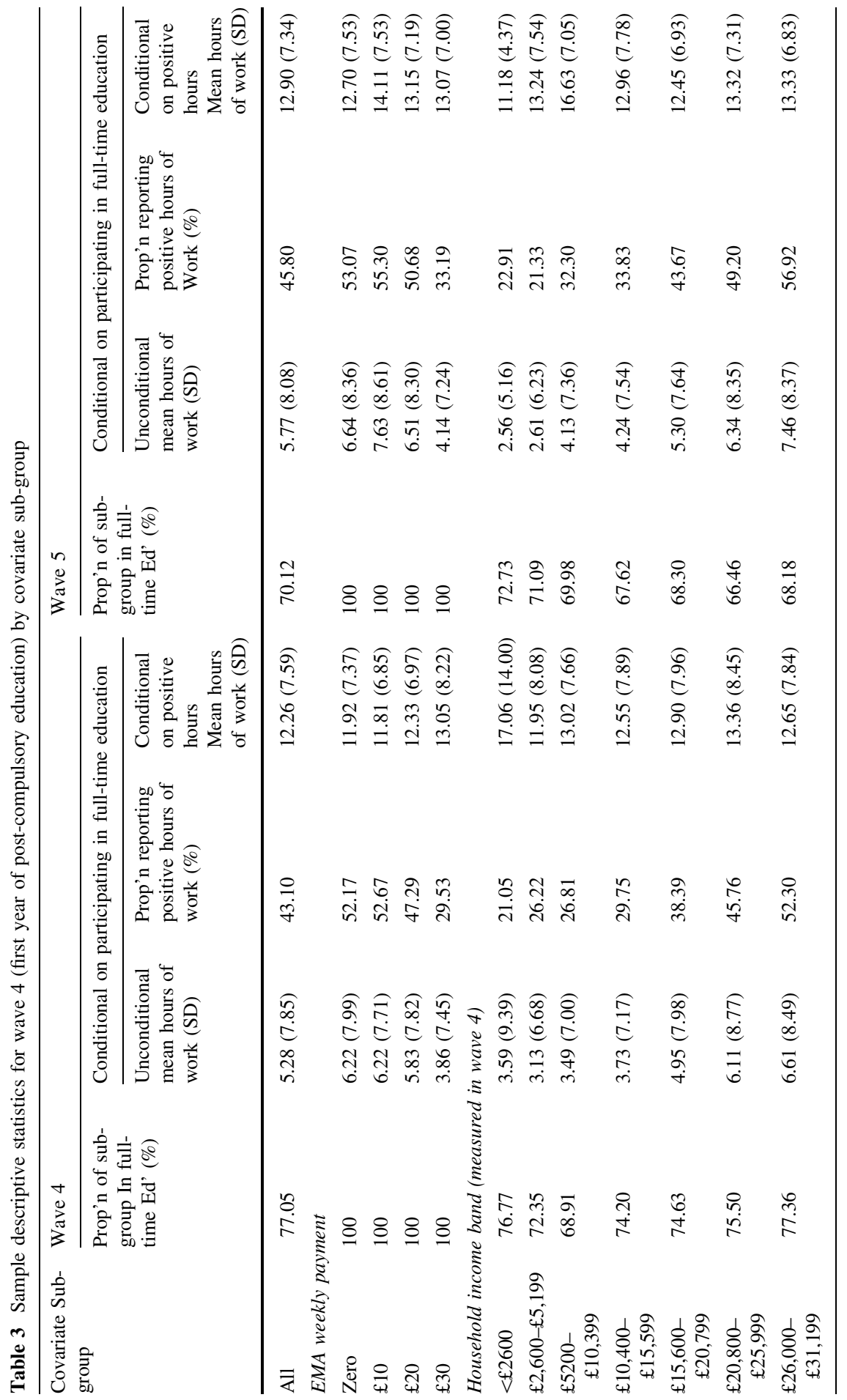




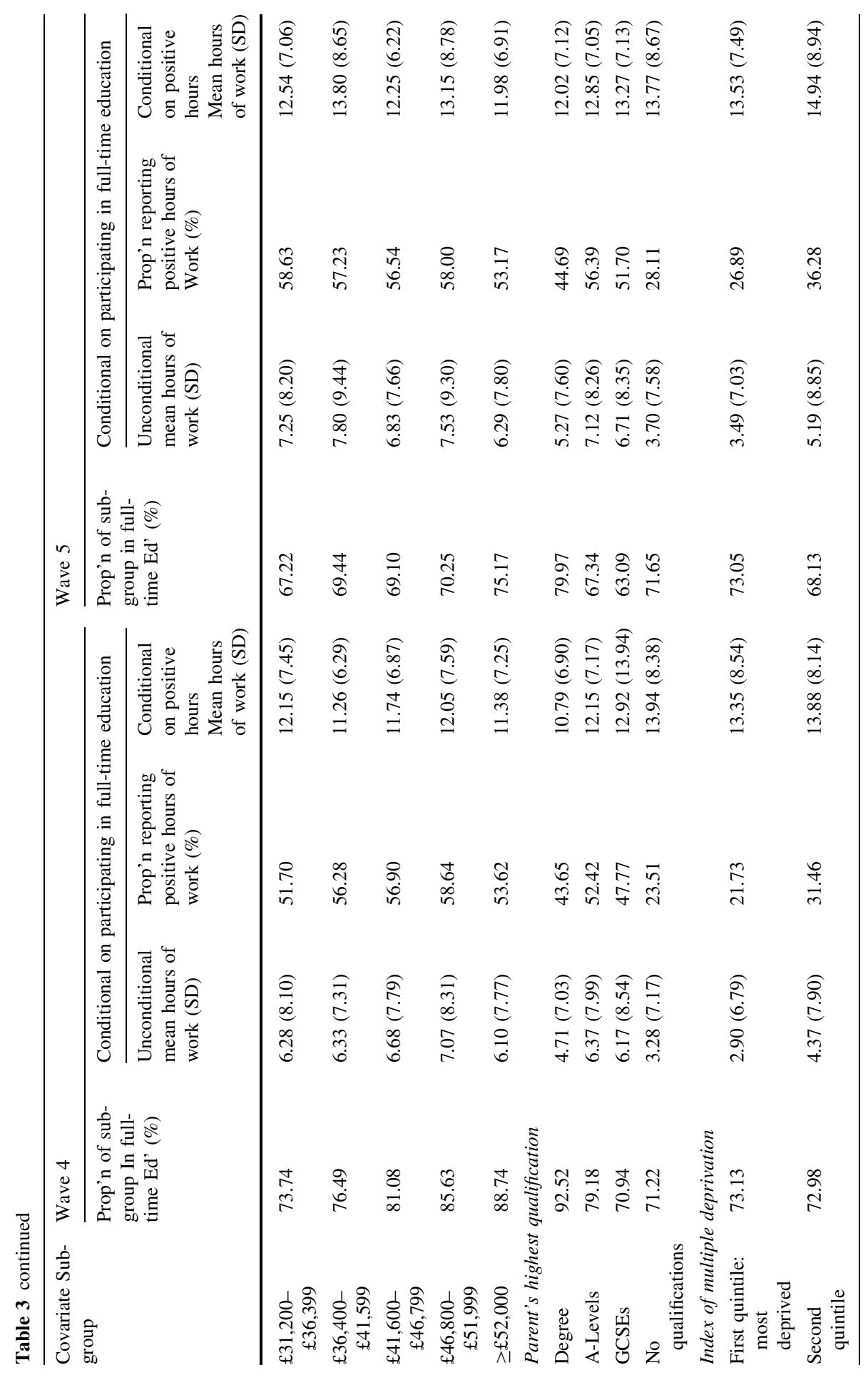




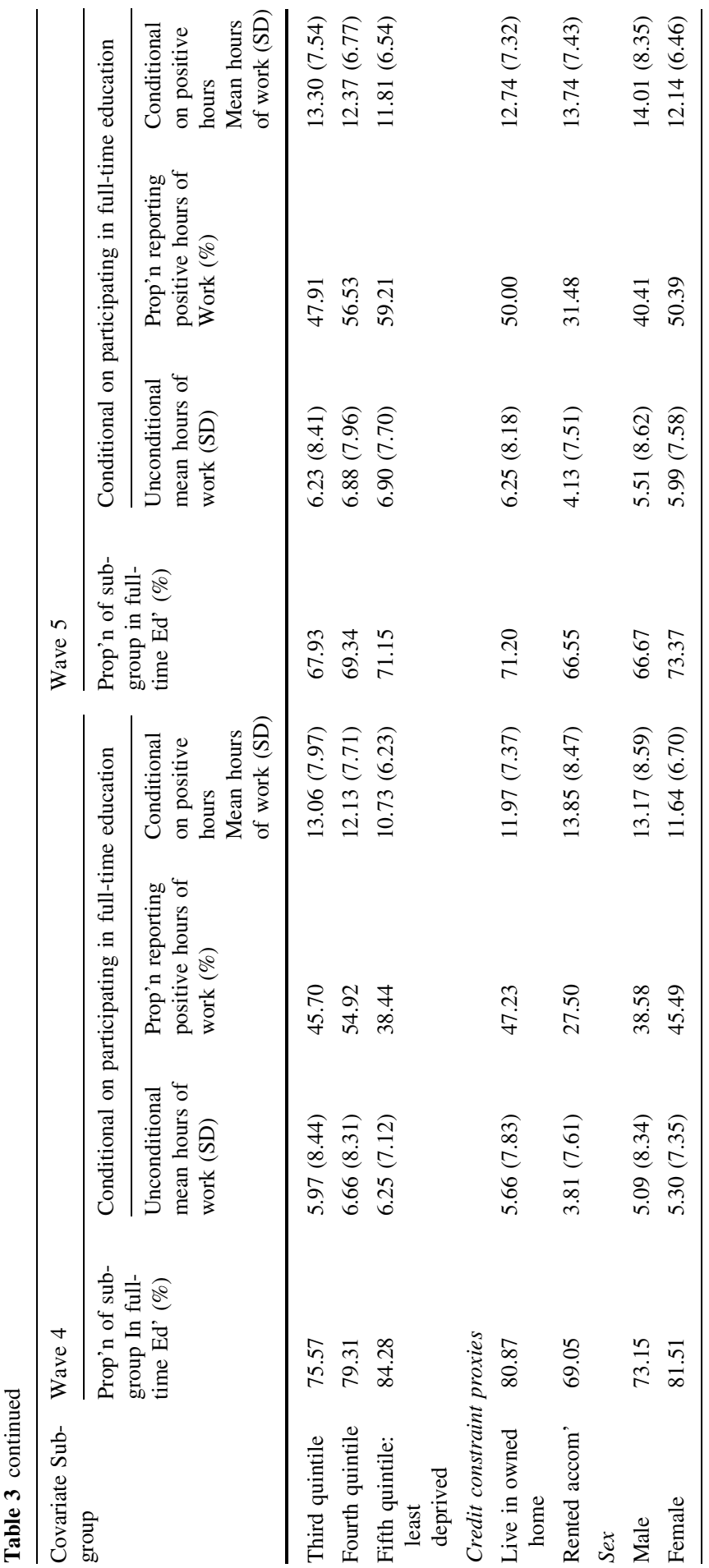


Those receiving EMA of $£ 30$ per week work substantially less than those receiving lower payments or none, but particularly in wave 5, this is substantially accounted for by the lower propensity to work at all, rather than a reduction in hours conditional on working. For this reason we shall present results for both the choice of hours, and the discrete choice to work positive hours.

\section{Results}

To estimate the effect of EMA on hours of employment we use Tobit regressions in cross-sectional and random-effects panel data specifications. We expect there to be unobserved heterogeneity in individuals' work opportunities or motivation, but individual fixed-effects cannot be conditioned out of the Tobit estimator, and implementing a fixed-effects Tobit with individual dummy variables will produce biased estimates. Therefore, we also present linear fixed- and random-effect specifications and Hausman tests for presence of this unobserved heterogeneity. Cross-sectional OLS regressions are also presented for an indication of the baseline conditional correlation between EMA receipt and the level of labour supply. In our linear specifications we treat observations with zero hours in the same way as those with positive hours. For the discrete choice to work positive hours we estimate logistic regressions with results presented as the odds ratio for working positive hours. The logit is chosen in preference to the probit because it enables the implementation of a conditional fixed-effects estimator. Our regressors of interest are dummy variables for receipt of $£ 10$, 20 , or $£ 30$ payments of EMA each week. Our standard errors account for clustered sampling at the school level.

We present our results in two parts, discussing firstly the results from estimates for the cross-section of children observed in their first year, and then in their second year, of post-compulsory schooling (aged 16-17, and 17-18 respectively). Secondly we present estimates exploiting changes in receipt of EMA over time within individuals due to (1) meeting the income eligibility criteria on entering the firstyear of post-compulsory education, and (2) transitioning into or out of eligibility between the first and second years of post-compulsory schooling.

\subsection{Cross-sectional specifications}

Estimates obtained using the cross-section of individuals in full-time education in waves 4 and 5 are shown in Table 4 . The results show a significant negative correlation between receipt of the highest category of EMA ( $£ 30$ per week) and both hours of employment and the probability of working positive hours, conditional on observed characteristics, and also a negative monotonic relationship between the size of EMA payments and their coefficient for labour supply (though the effect of the smaller payments is significant at, at best, only the $10 \%$ level). We note that to the extent to which unobserved motivation or labour market opportunities are negatively correlated with receipt of EMA, these downward represent biased estimates of the causal effect of EMA on child's labour supply. This exercise nevertheless provides an 
Table 4 Cross-sectional specifications: marginal effects on hours worked and probability of working positive hours

\begin{tabular}{|c|c|c|c|c|c|c|}
\hline \multirow[t]{3}{*}{ EMA } & \multicolumn{4}{|c|}{ Marginal effects on hours worked } & \multicolumn{2}{|c|}{$\begin{array}{l}\text { Odds ratios for probability of } \\
\text { working positive hours }\end{array}$} \\
\hline & \multicolumn{2}{|l|}{ OLS } & \multicolumn{2}{|l|}{ Tobit } & \multicolumn{2}{|l|}{ Logit } \\
\hline & Wave 4 & Wave 5 & Wave 4 & Wave 5 & Wave 4 & Wave 5 \\
\hline \multirow[t]{2}{*}{$£ 10$} & -0.323 & 0.044 & -0.285 & -0.464 & 1.003 & 0.895 \\
\hline & $(-0.421)$ & $(0.649)$ & $(0.791)$ & (1.174) & $(0.115)$ & $(0.142)$ \\
\hline \multirow[t]{2}{*}{$£ 20$} & $-0.686^{*}$ & -0.865 & $-1.430 *$ & $-1.919 *$ & 0.830 & 0.785 \\
\hline & $(0.283)$ & $(0.585)$ & $(0.838)$ & $(1.136)$ & $(0.097)$ & $(0.121)$ \\
\hline \multirow[t]{2}{*}{$£ 30$} & $-1.267 * * *$ & $-1.508 * * *$ & $-3.096 * * *$ & $-3.201 * * *$ & $0.662 * * *$ & $0.704 * * *$ \\
\hline & $(0.283)$ & $(0.362)$ & $(0.629)$ & $(0.778)$ & $(0.053)$ & $(0.066)$ \\
\hline $\mathrm{N}$ & 7517 & 4907 & 7517 & 4907 & 7561 & 5013 \\
\hline $\mathrm{R}^{2} /$ Pseudo $\mathrm{R}^{2}$ & 0.09 & 0.09 & 0.04 & 0.03 & 0.15 & 0.14 \\
\hline
\end{tabular}

Clustered standard errors in parentheses. * $p<0.1$; ** $p<0.05$; *** $p<0.01$. Additional controls: household income (measured at wave 4 in both specifications), socio-economic class, parent's highest qualification, local deprivation index, region, type of school attended, prior academic performance at age 11 and 14, quarter of birth, ethnicity, parental employment, sibling composition, lone parent, sex, free school meal eligibility

indication of the difference in the inference from the linear specification, which does not account for censoring at zero, and the Tobit, which does.

For example, the OLS estimates show the best linear prediction is that EMA of $£ 30$ per week reduces employment by $1.3 \mathrm{~h}$ per week in wave 4 , and $1.5 \mathrm{~h}$ in wave 5. The interpretation of the Tobit estimates, on the other hand, is that EMA of $£ 30$ per week reduces desired labour supply by just over $3 \mathrm{~h}$ per week on average (this figure accounts for individuals who reach zero hours but might still prefer more leisure and less consumption). The OLS coefficients are smaller in absolute value because observations of zero hours are treated in the same way as positive hours, meaning the observed effect of EMA is capped by the fact that hours worked cannot fall below zero. That EMA has a significant negative association with employment at the extensive margin is clear from the logit model. Receipt of $£ 30$ per week EMA reduces the odds of participation by slightly more than $30 \%$. The wave 4 and wave 5 odds ratios of 0.662 and 0.704 are equivalent to marginal effects on the probability of participation of -9.7 and -8.4 percentage points from a base of $43 \%$.

We note that, since we are controlling for wave 4 income in the wave 5 models (household income not being collected in wave 5), receipt of EMA in wave 5 will be negatively correlated with the measurement error in income. Households receiving EMA will on average have a lower income than accounted for by our observed covariates, meaning lower parental transfers and higher child employment. We expect this to positively bias our wave 5 results, towards a coefficient of zero or odds ratio of one. Nevertheless, the difference in coefficients between waves is never statistically significant. 


\subsection{Panel data specifications}

We now discuss estimates for the labour supply effect of EMA in fixed- and randomeffect panel data specifications. The purpose of controlling for individual fixed effects is to eliminate the effect of time invariant unobserved individual differences in motivation, ability, household resources or labour market opportunities, and so, provided there are no time-varying unobserved differences of this nature correlated with receipt of EMA within-person, to produce consistent estimates of the effect of EMA on labour supply. The random effects specifications are inconsistent in the presence of time-invariant unobserved effects correlated with EMA, but in their absence, constitute the more efficient estimator. We conduct Hausman tests for the presence of time-invariant unobserved effects, in order to select our preferred model.

These estimates are presented for the balanced panel of individuals observed in full-time education over two alternative time periods. Estimates of the labour supply effect of EMA are first shown for waves 3-4, the final year of compulsory and first year of post-compulsory schooling. No-one was eligible for EMA during compulsory schooling, so here the fixed-effect estimates are identified by transitions into receipt of EMA for those meeting the income criteria compared with those not meeting the income criteria on entering post-compulsory education. We next show results for waves $4-5$, the first 2 years of post-compulsory schooling, and during both of which EMA was available to all those meeting the income criteria. Here the fixed-effect estimates are identified by within-person transitions in receipt of EMA between the two waves. Here, however, because no data on household income is available in wave 5, there is likely to be an unobserved, time varying, reduction in household resources associated with a transition into receipt of EMA. This violates the identifying assumption of fixed-effects regression. Since a reduction in household resources will, other things equal, reduce parental transfers and increase labour supply, we expect this specification to produce positively biased coefficients for the labour supply effect of EMA.

We might also expect differences in the source of identification of these specifications to produce different results. In the wave 3-4 specification all of those who receive EMA in wave 4 undergo a transition, while in the wave 4-5 specification, only those who subsequently lose their EMA, or gain EMA for the first time, in wave five undergo a transition. This latter group is likely to come from more affluent households, with incomes closer to the eligibility threshold on average. On a related note, we also show that the standard errors in the fixed-effect specifications for waves 4-5 are approximately twice the size of those estimated for waves $3-4$, due to the smaller number of transitions in receipt of EMA contributing to identification. ${ }^{8}$

The results for the key coefficients on receipt of EMA from the models on both time periods are shown in Table 5. (The coefficients on the complete set of explanatory

\footnotetext{
${ }^{8}$ We also estimated on all three waves, and obtained results not statistically different from either specification presented here. We focus on our two wave models for clarity about the source of identification: in the three-wave model, the fixed-effect estimates are identified by changes in EMA receipt both due to meeting the income criteria on reaching the eligible age-group, and movements into and out of eligibility among those already old enough. As with the wave 4-5 specification, the 3-5 estimates are also biased by the absence of wave 5 income requiring us to treat income as time invariant.
} 
variables for all the specifications shown here are presented in Appendix Table 8). We may generally state from Table 5 that the monotonic relationship between the size of EMA payments and their coefficient in determining labour supply seen for the crosssectional results is borne out in all the specifications shown in Table 5, but that in all but one case (the random-effects linear regression for waves 4-5) the estimated effect of the highest payment of EMA is larger than seen in the cross-sectional estimates (reductions in hours between 1.7 and 2 per week, and odds of participation between 40 and $50 \%$, equivalent to between 12.1 and 15.5 percentage points).

Focusing on the linear fixed-effect specifications, we estimate from our wave 3-4 specification that a transition into receipt of $£ 30$ EMA on entering post-compulsory schooling reduces labour supply by $1.9 \mathrm{~h}$ per week: and from our wave 4-5 specification that a transition into EMA receipt during post-compulsory schooling reduces labour supply by $1.7 \mathrm{~h}$ per week. The wave $4-5$ coefficient is positively biased (towards zero) due to the omission of time varying household income from this specification, but in this case the Hausman test does not reject equality of the random and fixed-effects coefficient vectors, so we interpret the random effects coefficient here of $-1.3 \mathrm{~h}$ as a more efficient estimate of this upper bound.

Turning now to the participation decision at the extensive margin, the conditional fixed effects logit model produces consistent estimates for the wave 3-4 specification but (as with the wave 4-5 specification), the Hausman test rejects consistency of the more efficient random-effects logit. Our interpretation is therefore that receipt of $£ 30$ EMA reduces the odds of participation in employment by $43 \%$, or the probability by approximately 13 percentage points from the wave 4 level. Although we expect the omission of household income in the wave 4-5 model to produce positively biased estimates the odds ratio estimated for this period is only marginally closer to one, and not statistically or economically different.

Although for waves 4-5, the Hausman test cannot reject consistency of the linear random effects specification, the Hausman test does reject consistency of the random effects logit on participation. As a result, we are reluctant to make any claim about the consistency of the random-effects Tobit estimator in this context. Nevertheless, we note that the interpretation in the wave 4-5 specification, that receipt of EMA of $£ 30$ per week reduces desired labour supply by just over $3 \mathrm{~h}$ per week, is identical to that obtained in both waves' cross-sectional estimates, and larger in absolute value than its linear counterpart in the same proportion as for the cross-sectional estimates. The wave 3-4 estimate is somewhat smaller in absolute value (albeit both estimates have large standard errors and are not significantly different), with $£ 30$ per week EMA reducing desired labour supply by just $2.4 \mathrm{~h}$ per week.

Differences between our wave 3-4 and wave 4-5 results may also be due to heterogeneous effects driven by the composition of the treated group (those affected by changes in EMA receipt during post-compulsory education will be more affluent on average than those gaining EMA on entry into post-compulsory education), by the age of the cohort (parents' willingness to make transfers to their children, and children's relative valuation of consumption and leisure may change with increasing expectations of independence), and by the composition of the sample (those still observed in education in wave 5 will be more positively selected with respect to educational aspirations and expectations). Nevertheless, we point to the stability of 
Table 5 Panel data effects on hours worked and probability of working positive hours

\begin{tabular}{|c|c|c|c|c|c|}
\hline & \multicolumn{3}{|c|}{ Marginal effects on hours worked } & \multirow{2}{*}{\multicolumn{2}{|c|}{$\begin{array}{l}\text { Odds ratios for probability of } \\
\text { working positive hours } \\
\text { Logit }\end{array}$}} \\
\hline & \multicolumn{2}{|c|}{ Linear regression } & \multirow{2}{*}{$\begin{array}{l}\text { Tobit } \\
\text { Random- } \\
\text { effects }\end{array}$} & & \\
\hline & $\begin{array}{l}\text { Random- } \\
\text { effects }\end{array}$ & $\begin{array}{l}\text { Fixed- } \\
\text { effects }\end{array}$ & & $\begin{array}{l}\text { Random- } \\
\text { effects }\end{array}$ & $\begin{array}{l}\text { Conditional fixed- } \\
\text { effects }\end{array}$ \\
\hline \multicolumn{6}{|l|}{ Waves 3-4 } \\
\hline EMA $£ 10$ & $\begin{array}{l}-0.088 \\
(0.408)\end{array}$ & $\begin{array}{l}0.307 \\
(0.415)\end{array}$ & $\begin{array}{l}0.262 \\
(0.742)\end{array}$ & $\begin{array}{l}1.054 \\
(0.145)\end{array}$ & $\begin{array}{l}0.950 \\
(0.216)\end{array}$ \\
\hline EMA $£ 20$ & $\begin{array}{l}-0.666^{*} \\
(0.395)\end{array}$ & $\begin{array}{l}-0.774 \\
(0.431)\end{array}$ & $\begin{array}{l}-1.125 \\
(0.729)\end{array}$ & $\begin{array}{l}0.767 * * \\
(0.102)\end{array}$ & $\begin{array}{l}0.608 * * \\
(0.124)\end{array}$ \\
\hline EMA $£ 30$ & $\begin{array}{l}-1.781 * * * \\
(0.208)\end{array}$ & $\begin{array}{l}- \\
1.869 * * * \\
(0.203)\end{array}$ & $\begin{array}{l}-2.358 * * * \\
(0.408)\end{array}$ & $\begin{array}{l}0.592 * * * \\
(0.046)\end{array}$ & $\begin{array}{l}0.574 * * * \\
(0.062)\end{array}$ \\
\hline Hausman test & 37.64 & & - & 26.75 & \\
\hline$\chi^{2}(p$ value $)$ & $(0.0003)$ & & & $(0.0134)$ & \\
\hline $\begin{array}{l}\mathrm{R}^{2} \mid \mathrm{Log} \\
\quad \text { (pseudo)likelihood }\end{array}$ & $\begin{array}{l}0.1656 \\
\text { Overall }\end{array}$ & $\begin{array}{l}0.2187 \\
\text { Within }\end{array}$ & $-25,152.63$ & -8196.90 & -1230.12 \\
\hline $\mathrm{N}$ & 7150 & 7150 & 7150 & 8046 & 2387 \\
\hline \multicolumn{6}{|l|}{ Waves 4-5 } \\
\hline EMA $£ 10$ & $\begin{array}{l}-0.355 \\
(0.395)\end{array}$ & $\begin{array}{l}-0.894 \\
(0.621)\end{array}$ & $\begin{array}{l}-1.035 \\
(0.770)\end{array}$ & $\begin{array}{l}0.849 \\
(0.131)\end{array}$ & $\begin{array}{l}0.902 \\
(0.289)\end{array}$ \\
\hline EMA $£ 20$ & $\begin{array}{l}-0.791 * * \\
(0.369)\end{array}$ & $\begin{array}{l}-0.957^{*} \\
(0.565)\end{array}$ & $\begin{array}{l}-1.780 * * \\
(0.775)\end{array}$ & $\begin{array}{l}0.731 * * \\
(0.112)\end{array}$ & $\begin{array}{l}0.871 \\
(0.313)\end{array}$ \\
\hline EMA $£ 30$ & $\begin{array}{l}-1.311 * * * \\
(0.245)\end{array}$ & $\begin{array}{l}- \\
1.713^{* * * *} \\
(0.476)\end{array}$ & $\begin{array}{l}-3.219 * * * \\
(0.531)\end{array}$ & $\begin{array}{l}0.504 * * * \\
(0.051)\end{array}$ & $\begin{array}{l}0.560 * * \\
(0.154)\end{array}$ \\
\hline Hausman test & 9.91 & & - & 53.85 & \\
\hline$\chi^{2}(p$ value $)$ & $(0.3579)$ & & & $(0.0000)$ & \\
\hline $\begin{array}{l}\mathrm{R}^{2} \mid \mathrm{Log} \\
\quad \text { (pseudo)likelihood }\end{array}$ & $\begin{array}{l}0.0979 \\
\text { Overall }\end{array}$ & $\begin{array}{l}0.0388 \\
\text { Within }\end{array}$ & $-21,983.71$ & -5969.02 & -679.11 \\
\hline $\mathrm{N}$ & 4608 & 4608 & 4608 & 4745 & 1074 \\
\hline
\end{tabular}

Clustered standard errors in parentheses. * $p<0.1 ; * * p<0.05$, *** $p<0.01$. Hausman test conducted assuming no clusters. Conditional fixed-effect logit standard errors not cluster robust. Sample size for conditional fixed effects logit is number of individuals transitioning into or out of employment. $\mathrm{R}^{2}$ is 'overall $\mathrm{R}^{2}$, for random-effects regression, and 'within $\mathrm{R}^{2}$, for fixed-effects regression. Log likelihood reported for conditional fixed-effects logit, and log-pseudolikelihood for the random effects specifications. Additional controls: Time-varying: Household income (wave 3-4 specification only), type of school attended, parental employment, lone parent. Time invariant: Household income (not observed in wave 5, so held constant at wave 4 value in wave $4-5$ specification), socio-economic class, parent's highest qualification, local deprivation index, region, prior academic performance at age 11 and 14, quarter of birth, ethnicity,, sibling composition, sex, free school meal eligibility

the coefficients obtained with each estimator across the cross-sectional and panel data settings. From the linear and logit specifications, we argue that a representative range for the net labour supply effect of $£ 30$ per week EMA is an 8-13\% percentage point 
reduction in the probability of working positive hours and a 1.25-1.9 reduction in actual hours worked per week, and that the reduction in desired hours is larger, and though not bounded, in the order of magnitude of 2.4-3.2 h per week.

\subsection{Inference on parental altruism}

The negative labour supply response we observe here, which is significantly different from zero in all specifications, is sufficient to reject that $\lambda=1$, representing 'full insurance' by parents. However, these estimates do not recover structural parameters regarding the magnitude of the parental response. For inference towards these, we appeal to results elsewhere in the literature. For the UK in 1974, Dustmann et al. (2009) indicate that 16-year-olds work $0.307 \mathrm{~h}$ less each week for each additional $£ 1$ transferred from parents. For the US in 1997, Wulff Pabilonia (2001), indicates that the earnings of 16-year-olds fell by $\$ 0.654$ per $\$ 1$ of parental transfer. If children in the UK reduce their earnings by the same proportion per pound of parental transfer, then at the median wage of those working positive hours in our estimation sample (£4.77) this equates to children working $0.137 \mathrm{~h}$ per week less for every pound received in additional transfers.

The ratio of the labour supply response to EMA (taking into account the reduction in transfers made by the parents) to either estimate of the child's labour supply response to all unearned income gives an estimate for the net increase in the child's unearned income, or equivalently, the amount of his EMA which the child is permitted to 'keep'. In their estimates, both Dustmann et al. (2009) and Wulff Pabilonia (2001) account for the censoring of hours worked at zero, so using this strategy it is the desired reduction in labour supply, rather than linear prediction, which enables identification of the parameter of interest, $\lambda$.

Our Tobit results suggest that, on receiving an EMA payment of $£ 30$ per week, a teenager would, on average, like to reduce his labour supply by between 2.4 and $3.2 \mathrm{~h}$. Assuming that the child treats cash from parents as a perfect substitute for cash from the state, and his labour supply response to unearned income is equal to $0.307 \mathrm{~h}$ per pound per week (as in Dustmann et al. 2009), this implies a net increase in unearned income of between $£ 7.82$ and $£ 10.42$. Repeating this exercise using the income-responsiveness of $0.137 \mathrm{~h}$ per pound per week obtained from Wulff Pabilonia (2001) give a range of $£ 17.52$ to $£ 23.36$. Alternatively stated, in response to a weekly EMA payment of $£ 30$, the parent withdraws cash transfers, extracts cash contributions or compels the child directly to purchase goods previously provided in kind, to a combined value at least $£ 6.64$ (in the theoretical framework set out here implying $\lambda=0.22)$ but less than $£ 22.18(\lambda=0.74)$ respectively. We acknowledge that, without being able to condition on individual fixed-effects, the direction of the bias in any individual Tobit estimate is indeterminate. However, the overall bias must be smaller than that from the linear random-effects specification, which is affected by the same omitted variables bias but additionally that caused by failure to account for censoring at zero, which operates in the same direction. Therefore, repeating this exercise using the coefficient obtained in the wave 4 OLS specification $(-1.267 \mathrm{~h}$, the smallest in absolute value), we place a lower bound on the net gain in unearned income of $£ 4.13$, giving $\lambda=0.86$. 
The condition for parental behaviour to be consistent with an effective altruist redistributing income to maximise household welfare is $\lambda=(1-\theta)$, where $\theta$ is the parent's marginal propensity to transfer cash to the child out of their own income. Dustmann et al. (2009) estimate $\theta=0.005$, and at the mean parental income for each sample subgroup, Kalenkoski and Wulff Pabilonia (2010) estimate $\theta=0.015$ for 2-year and 0.032 for 4-year college students. These figures correspond to $(1-\theta)=0.995,0.985$, and 0.968 respectively. The estimates of $\lambda$ calculated above are all considerably smaller than this. Though ours is a rough calculation using parameters obtained from different institutional backgrounds, the net effect of EMA has clearly been to raise the child's unearned income by substantially more than had the equivalent transfer been made by parents. Thus, we reject both the 'full insurance' and 'effective altruist' hypotheses.

\subsection{Robustness checks}

We now show that this conclusion is robust to a series of sensitivity checks. Results for a series of sub-groups of the population; by household credit constraint, time of interview, and gender; are shown in Table 6, estimated using eight of the specifications discussed above. We do not show the wave 5 cross-sectional estimates, which are likely to be most biased by measurement error in household income, or the random effects linear and logit specifications, showing instead their (conditional-) fixed-effect counterparts. Results for the whole estimation sample, but with subsets of control variables omitted to reduce multicollinearity among the covariate vector, are shown in Table 7, again for eight specifications. There we omit the fixed-effect estimators (since the regressors we omit, all time invariant, have no bearing on the coefficients obtained) and their random-effect counterparts, but show the random-effects Tobit results.

\subsubsection{Non-credit-constrained sub-group}

Following the reasoning of Dearden et al. (2009), EMA is less likely to be a binding consideration in the child's education participation decision for the children of noncredit-constrained parents, here defined as those living in owner-occupied accommodation. Any bias due to endogenous selection into post-compulsory education should not be present for this reduced sub-sample. The marginal effects of interest for this group are presented in the top section of Table 6.

For the non-credit-constrained group, like the whole sample estimates, across the first seven specifications the magnitude of the labour supply effect is greater for EMA payments of $£ 30$ than of $£ 20$ and in turn $£ 10$, with only the estimates for $£ 30$ being persistently significant at the 5 or $1 \%$ levels. (In common with all the subsamples shown in Table 6 , there are very few transitions into and out of employment between waves 4 and 5, producing very imprecise and in some case incorrectly directioned, though never statistically significant, estimates of the odds ratio in the wave 4-5 conditional fixed effect logit estimates. We do not discuss these further).

The Tobit estimates show the $£ 30$ payment to reduce the desired labour supply of children in non-credit-constrained households by between 22 and 48 min more per week than estimated for the overall population, though the difference in coefficients 


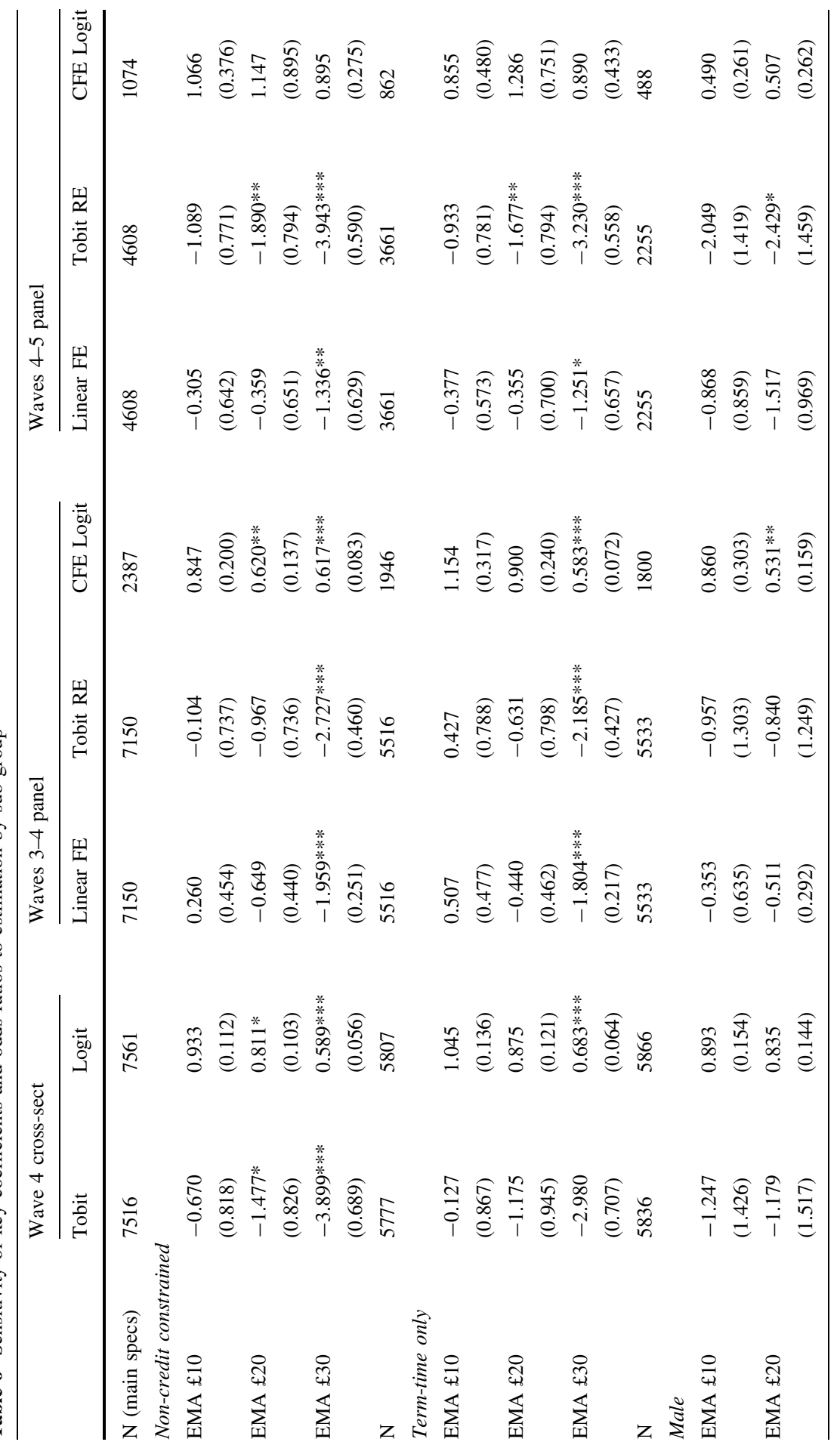




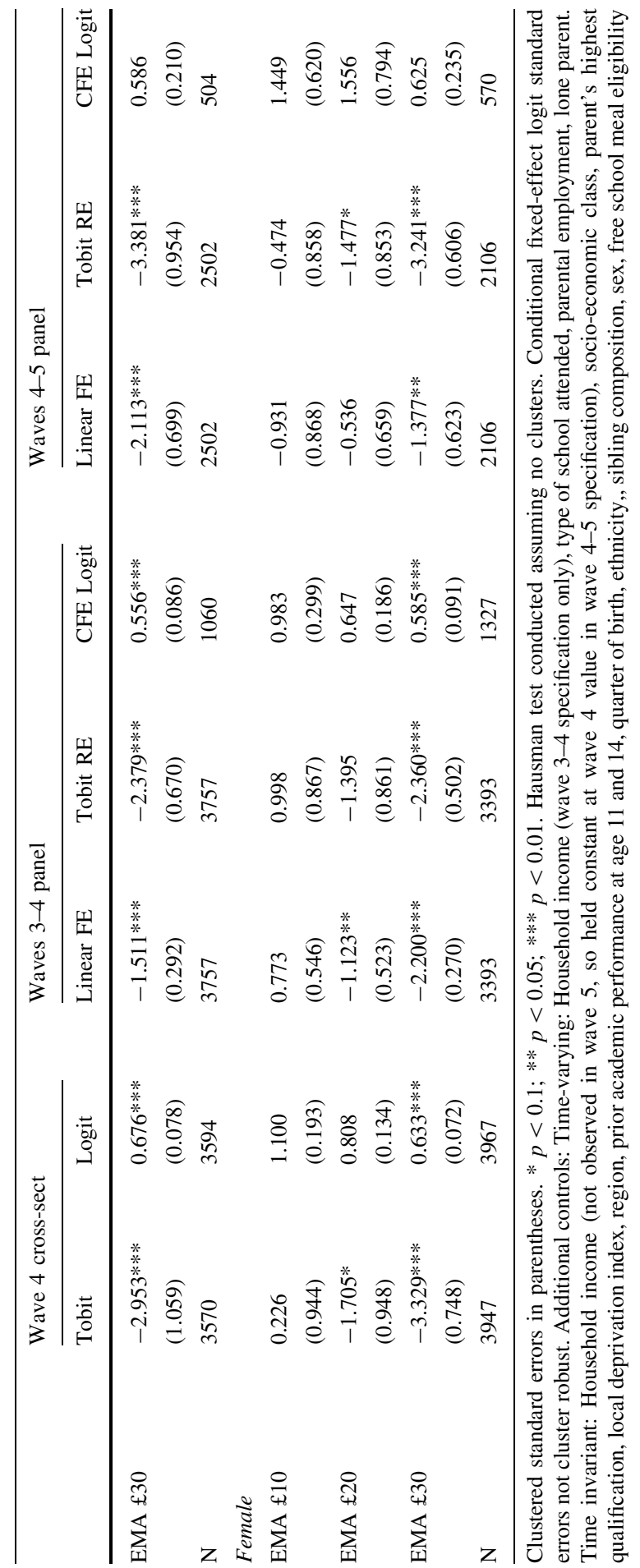




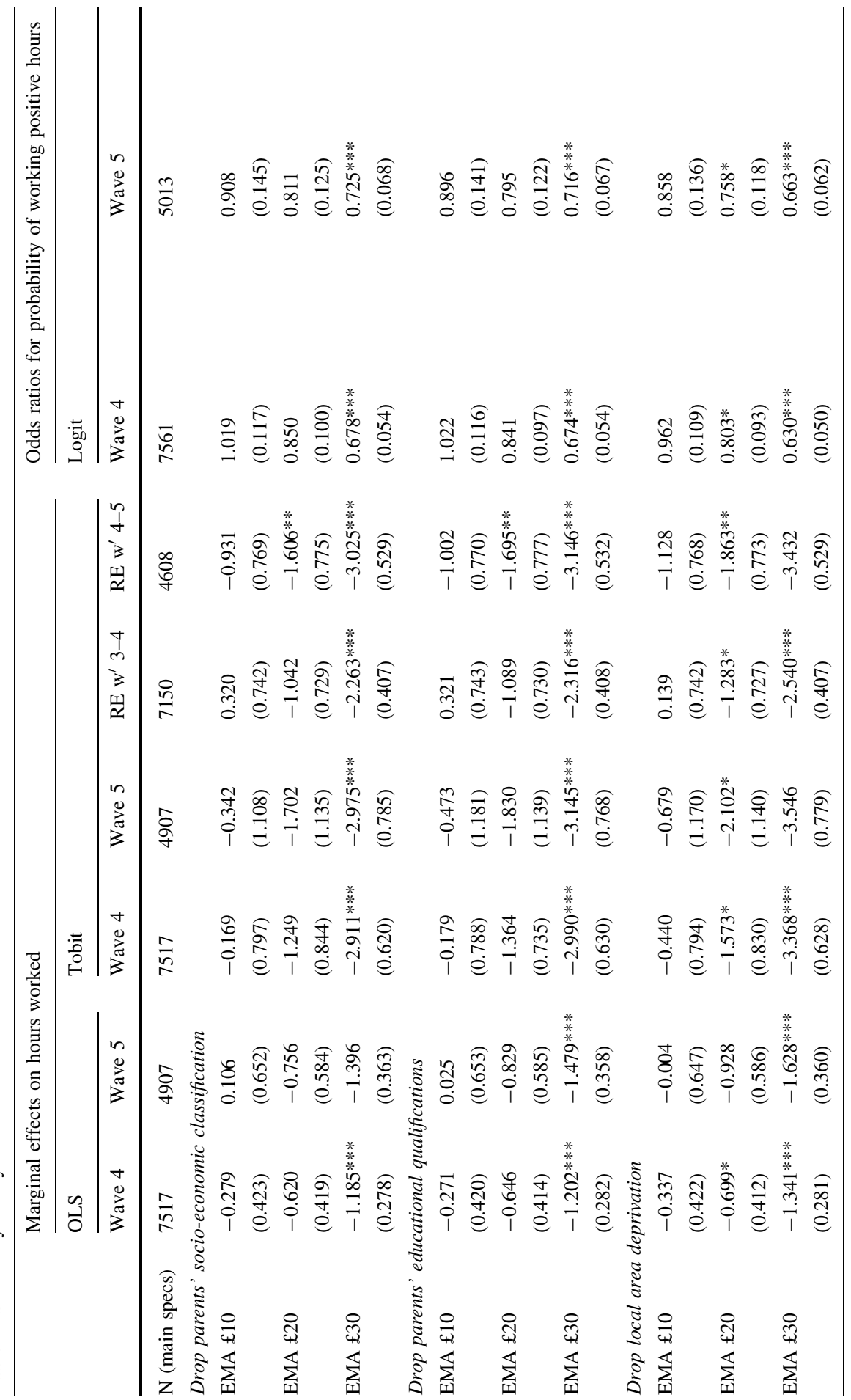




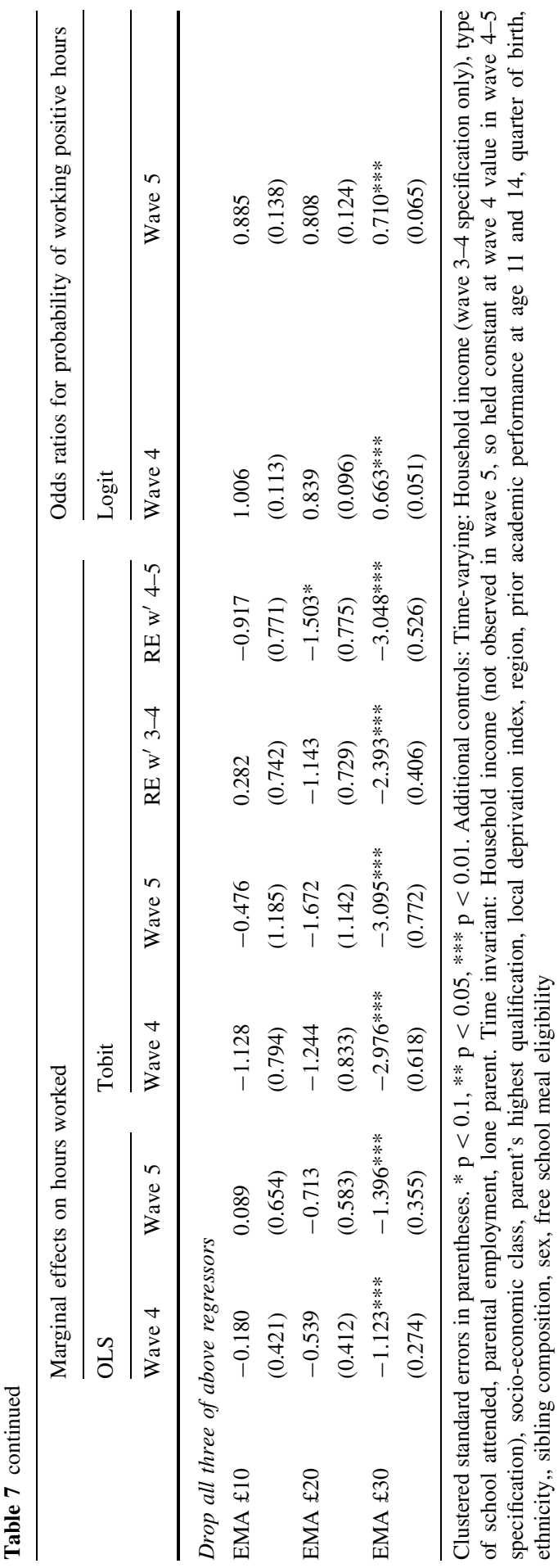


is not statistically significant. The wave $4-5$ linear specification produces a small and insignificant difference in the opposite direction, while differences in the remaining coefficients are trivial.

This finding adds robustness to our rejection of the effective altruist model. Parents in credit constrained households are more likely than those from non-credit-constrained households to lack the ability to redistribute resources to maximise household welfare but the balance of the estimates shown here suggests that altruistic redistributions are the same size or smaller in magnitude for the group most able to make them.

\subsubsection{Term-time interviews}

Some interviews took place in the school holidays, when EMA is not paid. The survey question about receipt of EMA asks "Do you get Education Maintenance Allowance?" In the main results shown here we assumed that interviewees respond according to what they receive during term time. We also assumed that the survey question regarding employment, emphasising hours "usually" worked, is interpreted to refer to term time, except in wave 3 , where this qualification is explicitly stated in the question. Except for the appreciable reduction in the sample size and resulting loss of precision, the results for those interviewed outside August in wave 4 and JulySeptember in wave 5, demonstrate no statistically significant changes compared with the whole population sample. In most cases the size of the change is also economically trivial, with the exception that in the wave 4-5 linear FE specification the $£ 30$ payment reduces labour supply by around 30 min per week less.

\subsubsection{Gender differences}

Distinct coefficients by gender could result from a greater responsiveness of labour supply to unearned income among female teenagers than males, but could also be due one of the following explanations. Firstly, a larger proportion of males than females may be induced by EMA to participate in post-compulsory education (Dearden et al. 2009 , p. 830), so other things equal, this selection bias will be stronger among males than females. Secondly, the partial correlation of EMA take-up with unobservable characteristics determining labour supply may be stronger for one gender than the other. Thirdly may it be the case that parents let daughters 'keep' a different proportion of unearned EMA income than their sons. Nevertheless, the third and fourth sections of Table 6 show no appreciable differences in the labour supply effect of the highest EMA payment, with the exception of the linear fixed effect estimates. The coefficient is considerably more negative for girls in waves 3-4 (equivalent to $41 \mathrm{~min}$ greater reduction, and marginally significant), with the positions reversed at waves $4-5$, though such is the imprecision of these later estimates that the gap is no longer significant.

\subsubsection{Sensitivity to covariate vector}

We acknowledge the potential for the correlation between EMA receipt and several of the dummy variable covariate sets used in estimation to induce a problem of multicollinearity, inflating the variance of the estimates for the effect of EMA on 
labour supply. Table 7 shows results obtained when, in turn, parent's socioeconomic classification, parent's educational qualifications, and local area deprivation, are omitted from the vector of covariates.

There are no statistically or economically significant changes in the conclusions drawn from these specifications, compared with the complete covariate set. However, very tentatively, it can be seen that across the specifications, the direction of the bias is negative when the dummies for 'higher' deprivation than the omitted category are excluded (these being positively correlated with EMA and negatively determining labour market opportunities), and is positive when dummies for 'higher' socio-economic status and parental qualifications are omitted (these being negatively correlated with EMA and, we would expect, positively determining the child's employability). Therefore, it is likely that these new results reflect changes due to the expected bias, rather than providing evidence for collinearity having an impact on coefficients in the main specification. As a final robustness check, we additionally show results obtained when all three of these variables are omitted. From the final section of Table 7 it is clear that the results again remain stable, and that the improvement in precision is minimal.

\section{Discussion and conclusions}

We have shown that an EMA cash transfer of $£ 30$ per week causes a statistically and economically significant reduction in the labour supply of teenagers in full-time education at both the intensive and extensive margin. The effects of $£ 10$ and $£ 20$ payments are smaller in magnitude and less precisely estimated. This labour supply response is one mechanism by which EMA is likely to have improved educational and labour market outcomes for recipients, especially among those working the longest hours. Although later waves of the LSYPE collect retrospective data on educational performance at age 17 and 18, and allow us to observe progression into Higher Education and the labour market, we do not evaluate the magnitude of this effect here. There are other mechanisms by which EMA may have a direct effect on performance, such as through raising individuals' educational expectations and aspirations, or selfesteem of individuals with a greater independent resource, which mean EMA is unlikely to be a valid instrumental variable. The endogenous selection into postcompulsory schooling induced by EMA would also represent a significant challenge to causal inference.

Instead, the focus of this paper has been to use the labour supply effect of EMA for inference regarding the altruistic behaviour of parents. We developed a theoretical model in which parents specify a transfer rule contingent on the child's labour supply, which children take as given when choosing their utility maximising hours of work. In this framework, EMA acts as an exogenous income shock received by the child as a cash transfer from the state. This contrasts with most existing empirical applications of Becker's (1974, 1981) 'effectively altruistic head of household' model, which consider the effects of in-kind transfers to children or hypothecated cash payments to parents. Though data deficiencies prevent structural identification of this model, our theoretical model shows the overall labour supply effect of EMA to depend on the degree to which parents redistribute household resources in response to EMA. 
The results obtained here reject the hypotheses that parents are 'effective altruists' or provide 'full insurance' for their child's consumption, but do suggest that for every pound the child receives from the state, the parent withdraws between $£ 0.22$ and $£ 0.86$ from the child. Although the child's welfare gain is greater than were the equivalent transfer to be made to parents, particularly towards the upper bound, the results do imply that a substantial proportion of the government's outlay is appropriated by the parents, rather than their children. With this in mind, if endogenous selection can adequately be addressed, we may follow the work of Ebens et al. (2011) for the Netherlands in identifying the extent to which grants supporting students from lowincome backgrounds participating in Higher Education crowd out parental support. This will enable a fruitful contribution to be made in evaluating the efficiency of 'widening participation initiatives' being implemented alongside the recent rise in university tuition fees in the UK. (The extent to which parents react differently to grants substituting for loans than to grants with no substitute in the same time period, may also provide lessons for improving the targeting of public transfers).

Our inference here relies on reasonable assumptions about the responsiveness of in-school labour supply to unearned income or resource endowments. Data pertaining to the cash and in-kind transfers made by parents to children receiving EMA would be required to identify the structural parameters and make inference regarding the magnitude of the parental response to EMA with greater robustness.

Teenagers in post-compulsory full-time education represent a unique component of the family for whom existing theories of parental altruism or provision are clearly insufficient. Exploration of the bargaining process undertaken by parents and teenagers in this situation would certainly be merited. It would also be interesting to learn whether this dynamic is affected by the current extension of compulsory education or training to the age of 18 in the UK. Data on a second cohort of young people in England ('LSYPE2' or 'Our Futures') is currently being collected (they will reach post-compulsory education in 2015-2016). This will provide an excellent resource to pursue both these questions.

Acknowledgments This work was carried out during integrated M.Sc. and Ph.D. studies at the Institute for Social and Economic Research, University of Essex. Thanks to Matthias Parey for his supervision and advice, Cheti Nicoletti for help with formative discussions, and Emilia Del Bono for her feedback. In particular, thank you to the editor, and to two anonymous referees whose comments helped improve the paper considerably. All errors are my own. This work was supported by an Economic and Social Research Council '1 + 3' studentship in Economics (Reference number ES/I025499/1).

Conflict of interest The author declares that he has no conflict of interest.

Open Access This article is distributed under the terms of the Creative Commons Attribution License which permits any use, distribution, and reproduction in any medium, provided the original author(s) and the source are credited.

\section{Appendix: Complete estimation output}

See Table 8. 


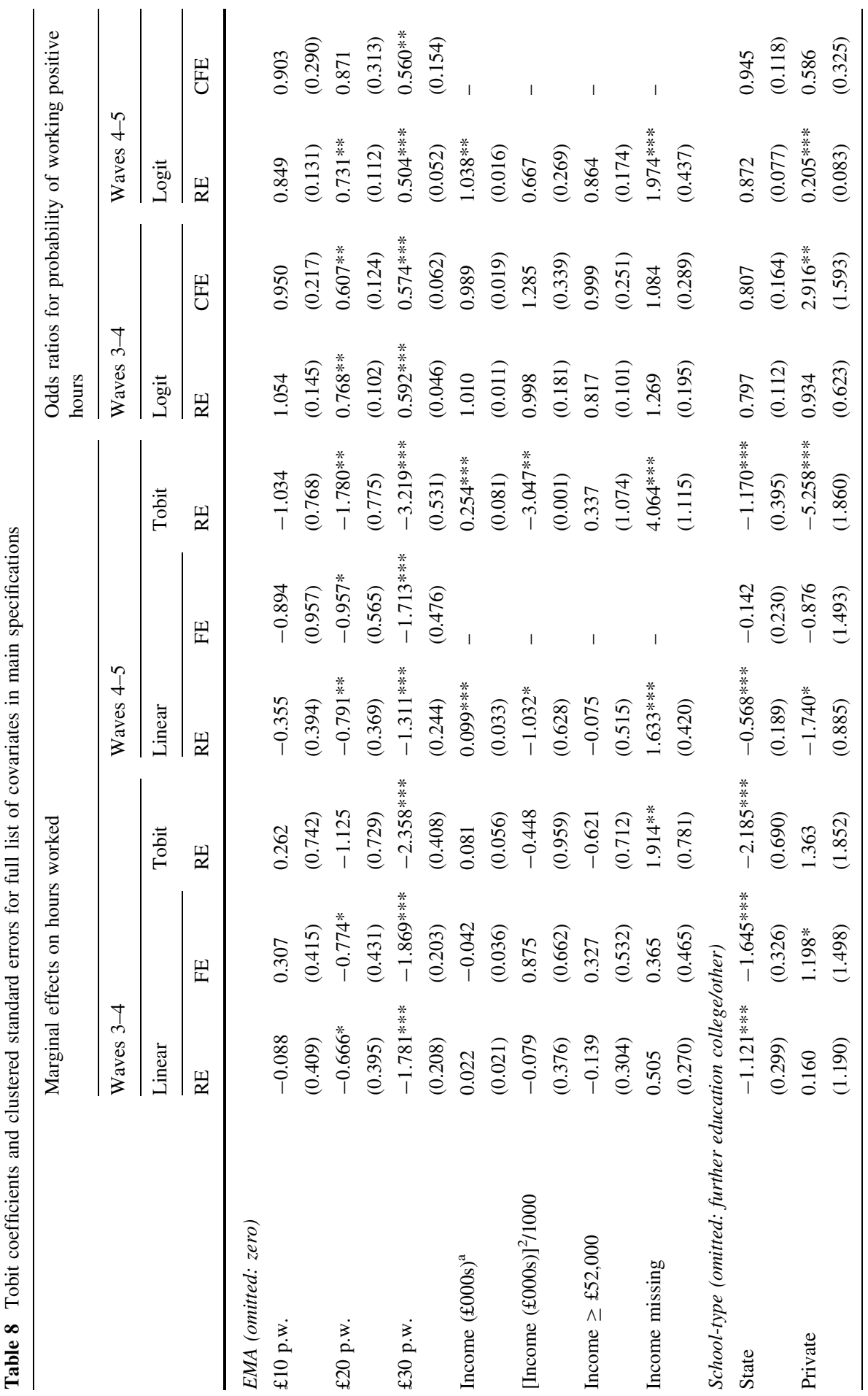




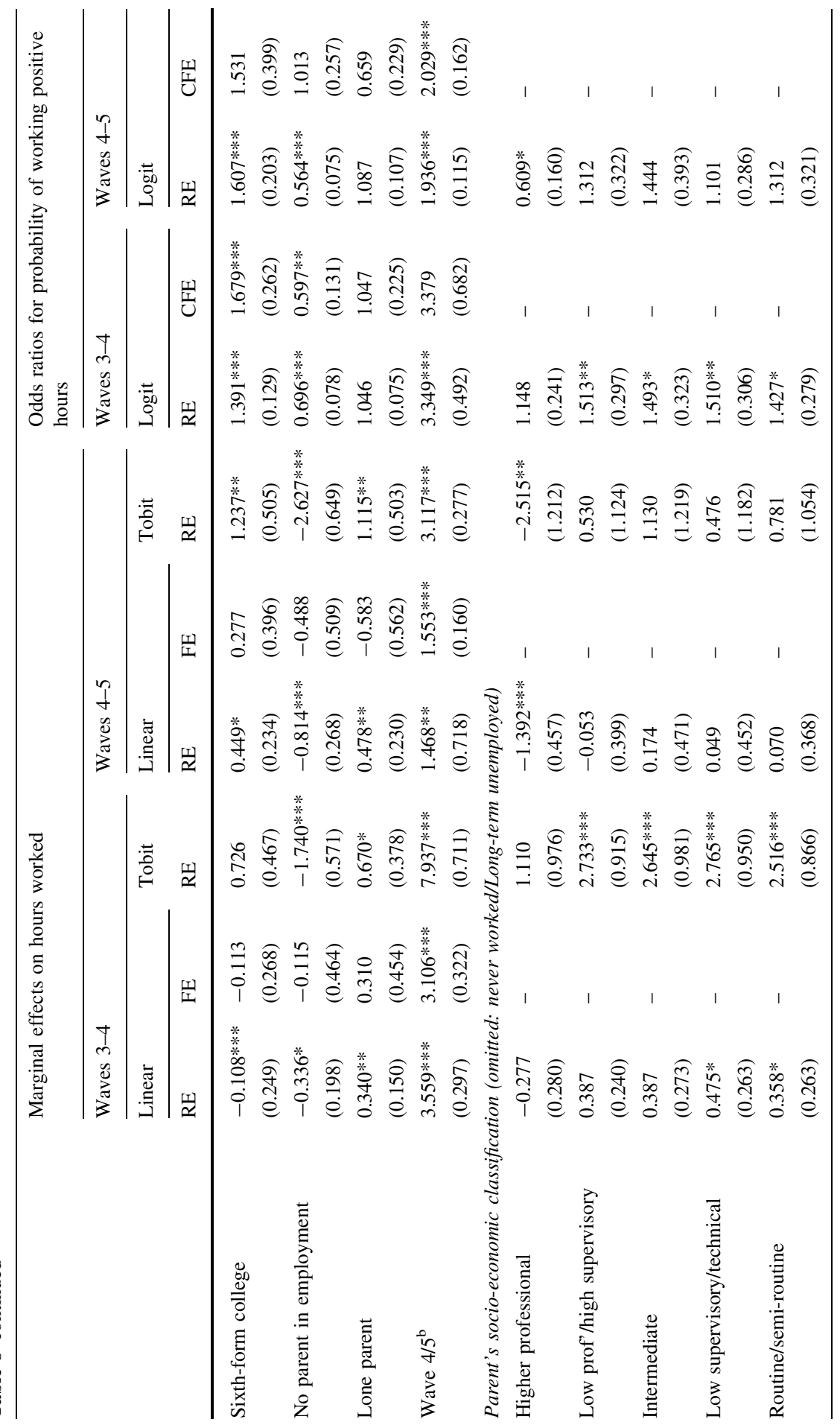




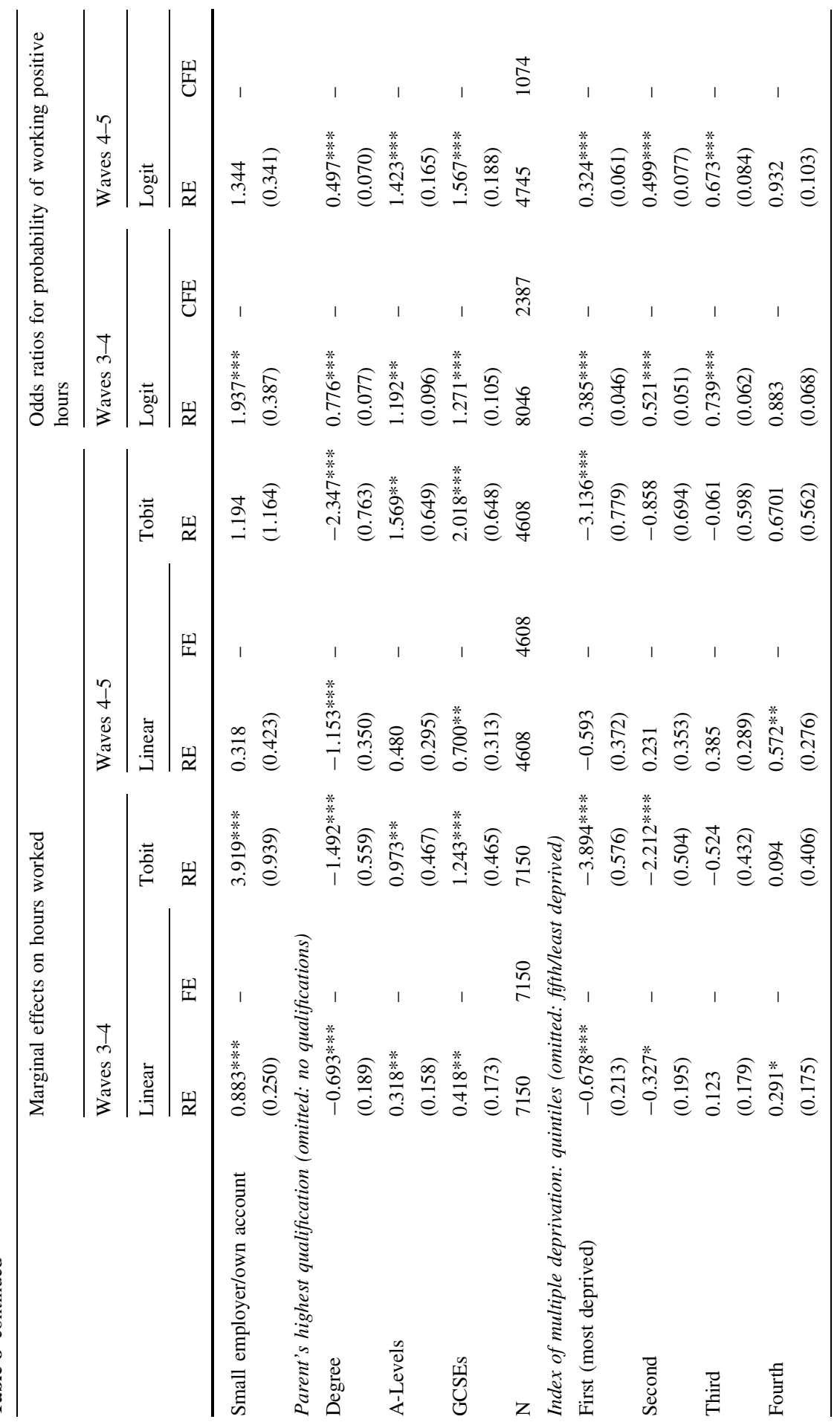




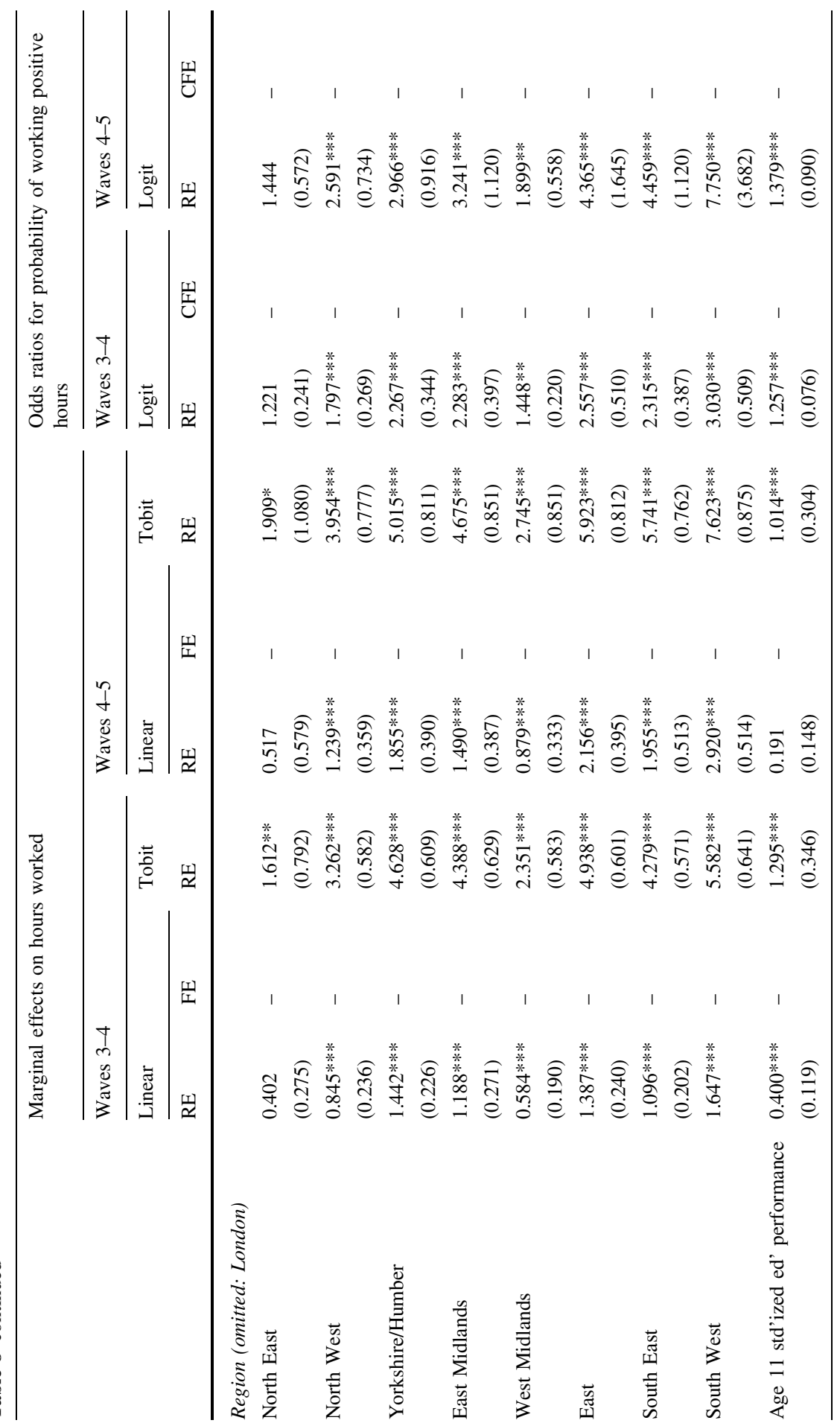




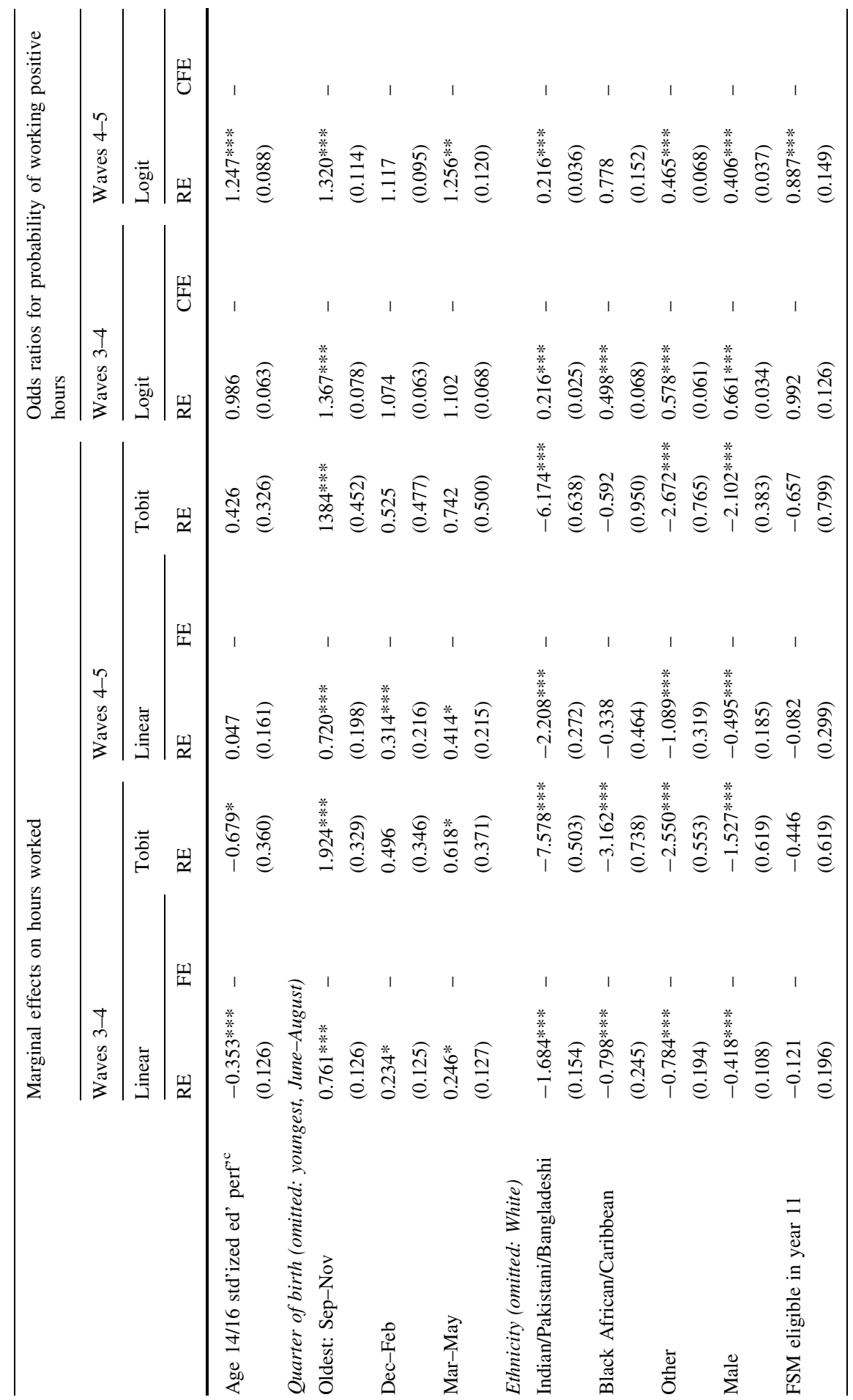




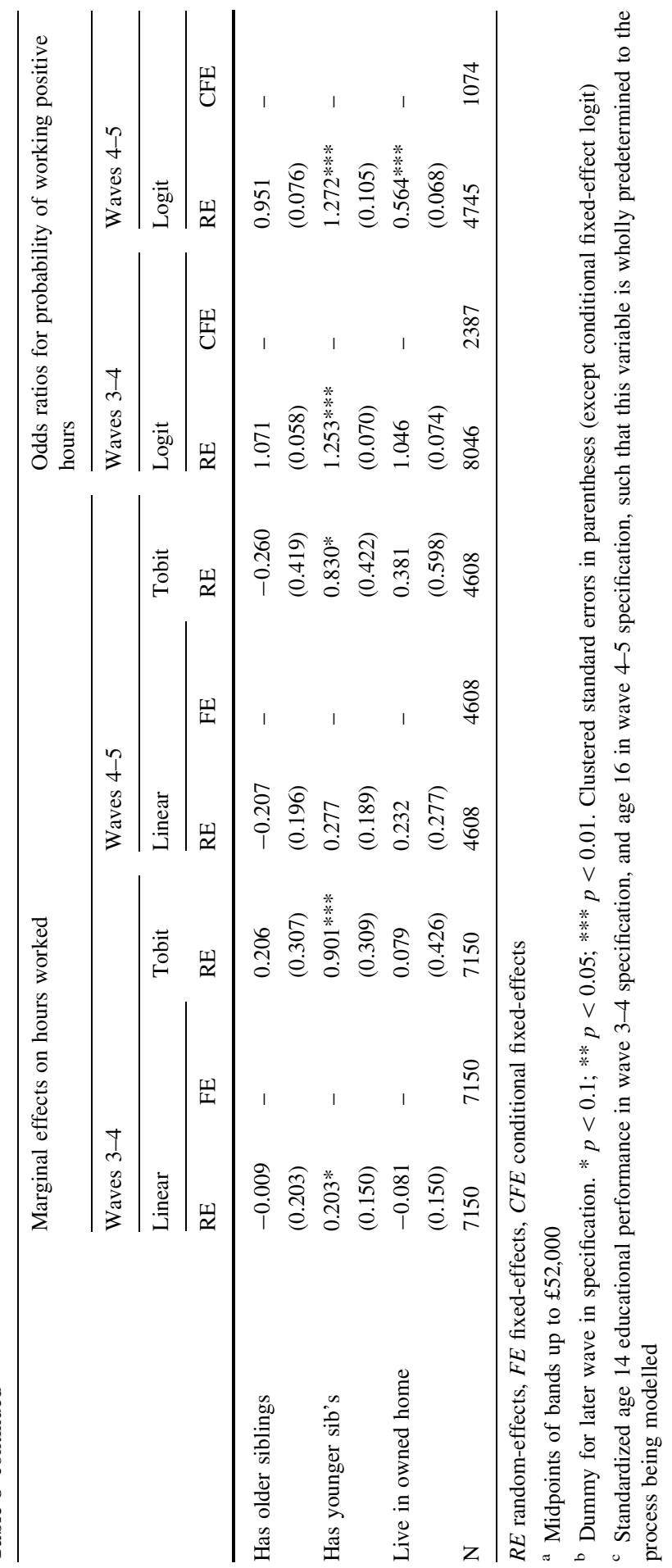




\section{References}

Attanasio, O., \& Mesnard, A. (2006). The impact of a conditional cash transfer programme on consumption in Colombia. Fiscal Studies, 27, 421-422.

Beatty, T., Blow, L., Crossley, T., \& O’Dea, C. (2014). Cash by any other name? Evidence on labelling from the UK Winter Fuel Payment. Journal of Public Economics, 118, 86-96.

Becker, G. (1974). A theory of social interactions. Journal of Political Economy, 82, 1063-1093.

Becker, G. (1981). Altruism in the family and selfishness in the market place. Economica, 48, 1-15.

Bingley, P., \& Walker, I. (2013). There's no such thing as a free lunch: Evidence of altruism and agency from household expenditure responses to child nutrition programs. Review of Economics of the Household, 5, 371-392.

Blow, L., Walker, I., \& Zhu, Y. (2012). Who benefits from child benefit? Economic Inquiry, 50, 153-170.

Bolton, P. (2011). Education Maintenance Allowance (EMA) statistics. House of Commons Library, Standard Note: SNSG/5778, London, UK. www.parliament.uk/briefing-papers/SN05778.pdf. Accessed July 12, 2011

Burton, P., Phipps, S., \& Curtis, L. (2002). All in the family: A simultaneous model of parenting style and child conduct. American Economic Review Papers and Proceedings, 92, 368-372.

Currie, J., \& Gahvari, F. (2008). Transfers in cash and in-kind: Theory meets the data. Journal of Economic Literature, 56, 333-383.

Dearden, L., Emmerson, C., Frayne, C., \& Meghir, C. (2009). Conditional cash transfers and school dropout rates. Journal of Human Resources, 44, 827-857.

Department for Education, National Centre for Social Research. (2012). Longitudinal Study of Young People in England: Waves One to Seven, 2014-2010, [computer file], 12th Edn. Colchester, Essex: UK Data Archive [distributor], study number 5545. doi:10.5255/UKDA-SN-5545-3

Dustmann, C., Micklewright, J., \& van Soest, A. (2009). In-school labour supply, parental transfers and wages. Empirical Economics, 37, 201-218.

Dustmann, C., \& van Soest, A. (2007). Part time work, school success and school leaving. Empirical Economics, 32, 277-299.

Ebens, M., van Elk, R., Webbink, D., \& Booij, A. (2011). The effect of the supplementary grant on parental contribution. CPB Discussion Paper No. 187.

Gong, T. (2009). Do parental transfers reduce youths' incentives to work? Labour: Review of Labour Economics and Industrial Relations, 23, 653-676.

Hoddinott, J., \& Skoufias, E. (2004). The impact of PROGRESA on food consumption. Economic Development and Cultural Change, 53, 37-61.

Jacoby, H. G. (2002). Is there an intrahousehold flypaper effect? The Economic Journal, 112, 196-221.

Jensen, R. T. (2003). Do private transfers 'displace' the benefits of public transfers? Evidence from South Africa. Journal of Public Economics, 88, 89-112.

Kalenkoski, C. M., \& Wulff Pabilonia, S. (2010). Parental transfers, student achievement and the labor supply of college students. Journal of Population Economics, 23, 469-496.

Kalenkoski, C. M., \& Wulff Pabilonia, S. (2013). Time to work or time to play: The effect of student employment on homework, housework, screen time and sleep. Labour Economics, 19, 211-221.

Kooreman, P. (2000). The labeling effect of a child benefit system. American Economic Review, 90, $571-583$.

Light, A. (2001). In-school work experience and the returns to schooling. Journal of Labor Economics, 19, 65-93.

Lillydahl, J. (1990). Academic achievement and part time employment of high school students. Journal of Economic Education, 21, 307-316.

Lundberg, S., Pollak, R., \& Wales, T. (1997). Do husbands and wives pool their resources? Evidence from the United Kingdom child benefit. Journal of Human Resources, 32, 463-480.

Oettinger, G. (1999). Does high school employment affect high school academic performance? Industrial and Labor Relations Review, 53, 136-151.

Payne, J. (2004). The impact of part-time jobs in years 12 and 13 and qualification achievement. British Educational Research Journal, 29, 599-611.

Phipps, S., \& Burton, P. (1998). What's mine is yours: The influence of male and female incomes on patterns of household expenditure. Economica, 65, 599-613.

RCU Market Research. (2007). Evaluation of the EMA National Roll-out, 2007. http://readingroom.lsc. gov.uk/lsc/National/nat-emaevaluationreportnov07-jan2008.pdf. Accessed July 12, 2011. 
Rosenzweig, M. R., \& Wolpin, K. I. (1994). Parental and public transfers to young women and their children. American Economic Review, 84, 1195-1212.

Ruhm, C. (1997). Is high school employment consumption or investment? Journal of Labor Economics, $15,735-776$.

Schmidt, K. (1993). Reputation and equilibrium characterization in repeated games with conflicting interests. Econometrica, 61, 325-351.

von Hinke Kessler Scholder, S. (2013). School meal crowd out in the 1980s. Journal of Health Economics, 32, 538-545.

Wolff, F. (2006). Parental transfers and the labor supply of children. Journal of Population Economics, 19, 853-877.

Wulff Pabilonia, S. (2001). Evidence on youth employment, earnings and parental transfers in the National Longitudinal Study of Youth, 1997. Journal of Human Resources, 36, 795-822. 